\title{
Molecular mechanisms of hypoxia in cancer
}

\author{
Amarnath Challapalli $^{1} \cdot$ Laurence Carroll $^{2} \cdot$ Eric O. Aboagye ${ }^{2}$
}

Received: 8 March 2017/ Accepted: 21 April 2017/Published online: 11 May 2017

(c) The Author(s) 2017. This article is an open access publication

\begin{abstract}
Purpose Hypoxia is a condition of insufficient oxygen to support metabolism which occurs when the vascular supply is interrupted, or when a tumour outgrows its vascular supply. It is a negative prognostic factor due to its association with an aggressive tumour phenotype and therapeutic resistance. This review provides an overview of hypoxia imaging with Positron emission tomography (PET), with an emphasis on the biological relevance, mechanism of action, highlighting advantages, and limitations of the currently available hypoxia radiotracers.

Methods A comprehensive PubMed literature search was performed, identifying articles relating to biological significance and measurement of hypoxia, MRI methods, and PET imaging of hypoxia in preclinical and clinical settings, up to December 2016.

Results A variety of approaches have been explored over the years for detecting and monitoring changes in tumour hypoxia, including regional measurements with oxygen electrodes placed under CT guidance, MRI methods that measure either oxygenation or lactate production consequent to hypoxia, different nuclear medicine approaches that utilise imaging agents the accumulation of which is inversely related to oxygen tension, and optical methods. The advantages and disadvantages of these approaches are reviewed, along with individual strategies for validating
\end{abstract}

Eric O. Aboagye

eric.aboagye@imperial.ac.uk

1 Department of Clinical Oncology, Bristol Cancer Institute, Horfield Road, Bristol, United Kingdom

2 Department of Surgery and Cancer, Imperial College, GN1, Commonwealth Building, Hammersmith Hospital, Du Cane Road, London W120NN, United Kingdom different imaging methods. PET is the preferred method for imaging tumour hypoxia due to its high specificity and sensitivity to probe physiological processes in vivo, as well as the ability to provide information about intracellular oxygenation levels.

Conclusion Even though hypoxia could have significant prognostic and predictive value in the clinic, the best method for hypoxia assessment has in our opinion not been realised.

Keywords Hypoxia · MRI · Positron emission tomography $\cdot$ Hypoxia radiotracers

\section{What is hypoxia?}

Hypoxia generally refers to sub-physiologic tissue oxygen levels $(<5-10 \mathrm{mmHg})$. Tumour hypoxia, a hallmark of malignancy, is a common and important feature of the tumour microenvironment. It is the consequence of an oxygen delivery versus consumption mismatch that occurs when cell proliferation outstrips neoangiogenesis during tumour growth. This results in very low oxygen levels $(<5 \mathrm{mmHg}$ ) in tumours versus $40-60 \mathrm{mmHg}$ in healthy tissues [1]. Hypoxia can generally be classified as (1) perfusion-related (acute) hypoxia due to insufficient blood flow, (2) diffusion-related (chronic) hypoxia caused by an increase in diffusion distances with tumour expansion, and (3) anaemic hypoxia caused by a decrease in oxygen transport capacity [2]. The latter two are considered relatively stable, whereas the degree of acute hypoxia may change in a short time. Cancer cells respond differently to decreased oxygen tension by eliciting cell death or cell survival, which partially depends on the time of exposure to hypoxia. 
The origin of chronic hypoxia in human tumours was postulated by Thomlinson and Gray in 1955 [3]. Chronic hypoxia, also referred to as diffusion-limited hypoxia (DLH), is caused by consumption of oxygen by cells close to vessels, leaving inadequate oxygen for the cells further away from the vessels $(>100 \mu \mathrm{m}$ of capillary blood vessels), as demonstrated by means of phosphorescence lifetime imaging of R3230AC tumours in dorsal flap window chambers [4]. Chronic hypoxic changes are exacerbated in larger tumours and contribute to long-term cellular changes such as high frequency of DNA breaks, accumulation of DNA replication errors, potentially leading to genetic instability and mutagenesis [5, 6].

Brown and colleagues [7] were the first to present a second form of hypoxia: acute hypoxia. Acute hypoxia is an abrupt and brief exposure to short-term hypoxia (between a few minutes and up to $72 \mathrm{~h}$ ) which occurs consequent to fluctuations in tumour perfusion accompanying functionally and structurally defective vascular network in tumour (overdilated, hyperpermeable, tortuous, and disrupted), and associated with high-interstitial pressure of the extracellular matrix [8]. This leads to periods of better or worse oxygenation $[9,10]$ promulgating the lexiconcycling hypoxia [11]. Temporal occlusion of blood vessels caused by blood clots or tumour emboli can also cause acute hypoxia [12]. Acute hypoxia can lead to generation of high levels of reactive oxygen species (ROS) that can damage cells [13]. Cellular adaptations to these conditions have been enumerated and include decreasing oxidative metabolism and activating autophagy $[14,15]$. Increased radio-resistance of cancer cells $[13,16]$, induction of spontaneous metastasis [10, 17, 18], and genomic instability due to delayed DNA damage response and rapid p53-dependent apoptosis $[19,20]$ can also result from hypoxia, leading to an aggressive tumour phenotype.

Hypoxia represents a unique tumour vulnerability to be exploited in the context of newly emerging personalised medicine strategies. Undoubtedly, both chronic and acute tumour hypoxia directly affect clinical responses to therapy by influencing tumour growth, ability to metastasize, and resistance to cell death.

\section{Methods}

A comprehensive PubMed literature search was performed, identifying articles relating to types of hypoxia, biological significance of hypoxia, measurement of hypoxia, MRI methods, and PET imaging of hypoxia in preclinical and clinical settings, up to December 2016. Search terms that were used to identify such articles were "hypoxia imaging," "MRI," "FMISO", "FAZA", "FETNIM", "EF5",
"HX4", "RP-170", "Cu-ATSM", and "PET" or "positron emission tomography." Original publications in English were selected for inclusion in this review.

\section{Biology and clinical significance of hypoxia}

Tumour hypoxia is frequently seen in solid tumours, and tumour cells survive by activating different signalling pathways leading to a plethora of temporally or spatially heterogeneous changes in tumours (Table 1), elicited at different thresholds of oxygen tension [21-52]. In fact, during malignant growth, hypoxic regions are associated with increased genetic instability and more aggressive phenotype which correlate with tumour metastasis risk. Likewise, hypoxia causes unequivocal resistance to cancer treatments, such as reduced drug penetration, intrinsic chemoresistance (by mechanisms including loss of sensitivity to p53-mediated apoptosis or diminution of cell proliferation by metabolic stress), and resistance to ionizing radiation (reduced ability of oxygen to fix DNA lesions).

A number of biological consequences of low oxygen levels have been elegantly described by Höckel and Vaupel [53]. At $\mathrm{pO}_{2}$ levels less than $10-15 \mathrm{mmHg}$, cells become radioresistant and gene expression of hypoxia-regulated genes under control of hypoxia-inducible factor (HIF1) increases. Decreased adenosine triphosphate (ATP) synthesis is seen at $\mathrm{pO}_{2}$ levels less than $10 \mathrm{mmHg}$ and together with decreased protein synthesis leads to lower oxygen consumption by cells. Finally, $\mathrm{pO}_{2}$ levels less than $1 \mathrm{mmHg}$ reduce oxidative phosphorylation and conversely enhance glycolysis to maintain adequate ATP levels [54].

\section{Role of HIFlalpha}

Pathological hypoxia is a common microenvironment factor in tumours that facilitates cell survival and propagation of the tumour. The cross-talk between tumour and its microenvironment is essential for tumour survival [55]. Hypoxia-inducible changes not only affect tumour cells but also the tumour microenvironment [56]. Hypoxia-inducible factor 1 and 2 (HIF1 and HIF2, respectively) are oxygensensitive, heterodimeric transcription factors that act as key mediators of the cellular adaptation to low oxygen. HIF1 regulates glycolysis and pyruvate metabolism, and HIF-2 controls fatty acid metabolism. HIF1 is a heterodimeric protein consisting of HIF1alpha (oxygen regulated) and HIF1beta (constitutively expressed) dimers. Hypoxia stabilises HIF1alpha which stimulates expression of a variety of genes controlling metabolic pathways, $\mathrm{pH}$ regulation, angiogenesis, metastatic potential, DNA replication, protein synthesis, and treatment resistance, which (1) enhances cell survival via growth factor signalling and inhibition of 
Table 1 Signalling pathways activated by tumour hypoxia promoting cell survival

\begin{tabular}{ll}
\hline Signalling pathways & Comments \\
\hline Hypoxia inducible factor (HIF1) & Mediates tumour cell responses to hypoxia \\
[21-27, 38-51] & Glucose metabolism \\
& HIF1alpha regulates the switch from pyruvate catabolism and oxidative phosphorylation to glycolysis in \\
both hypoxic and normoxic cells, by activating the expression of glucose transporters (GLUT 1 and 3) \\
and glycolytic enzymes [39, 44, 47] \\
Lipid metabolism \\
HIF2 regulates fatty acid metabolism and induces significant changes in the expression of glycolipids and \\
glycoproteins [51]. \\
DNA repair
\end{tabular}

Tumour hypoxia increases mutation rate and decreases DNA repair resulting in genetic instability

Acute hypoxia can result in high levels of reactive oxygen species (ROS), which causes DNA damage and malignant progression upon reoxygenation $[38,43]$

Chronic hypoxia can also lead to accumulation of DNA replication errors or DNA breaks over time [49]

Apoptosis

HIF1 initiates hypoxia-mediated apoptosis (during prolonged severe hypoxia) by enhancing the expression of the several genes such as Bcl-2, p53, BNIP3, and BNIP3L [48].

Angiogenesis

Hypoxia induces the imbalance between pro- and anti-angiogenic factors' production, which results in chaotic blood vessel formation.

HIF1 is involved in all steps of blood vessel formation [40] by contributing to i) Endothelial progenitor cell (EPC) recruitment and differentiation into endothelial cells (ECs), by VEGF, FGF \& PDGF regulation, [42] ii) induction of matrix metalloproteinases (MMPs) and iii) recruiting smooth muscle cells and pericytes to stabilise blood vessels [45]. However, in tumours, new blood vessels are often abnormal, immature, leaky, and dysfunctional, resulting in hypoxia [40] [41]

Metastases

Contributes to metastases by altering cancer cell adhesion and motility [41], through regulation of epithelial-to-mesenchymal transition (EMT), which is characterised by a decrease in epithelialassociated and an increase in mesenchymal-associated gene expression [50], promotes migration and invasion abilities through induction of CXCR4, CA9, MMP [46]

Unfolded protein response (UPR) [28-32]

AKT-mTOR pathway [28]

Other down stream changes miRNAs [32]

Epigenetic changes [33, 34] p53 [35]

Metabolic changes [36, 37]
This is an oxygen-sensitive signalling pathway mediating cell survival under hypoxic conditions

UPR restores homeostasis by alleviating the ER stress due to accumulation of misfold proteins under hypoxic conditions

This is mediated through protein kinase R-like endoplasmic reticulum kinase (PERK), inositol-requiring protein 1 (IRP-1), and activating transcription factor 6 (ATF6), which induce hypoxia-associated metastases and radioresistance

Mediates cell survival under hypoxia

Hypoxia-induced inhibition of mTOR-complex will induce autophagy, similar to the ER-stress-induced UPR

These interact with target mRNA's thereby suppressing target gene and consequent protein expression, thus regulatingproliferation, apoptosis, angiogenesis and DNA repair

Chromatin alterations such as histone acetylation/deacetylation allow cells to adapt to hypoxic stress

$\mathrm{TH}$ is one of the earliest driving forces which leads to loss of p53 function during tumourigenesis leading to treatment resistance

Hypoxia causes tumour cells to switch to glycolysis for energy production (due to decrease in mitochondrial oxidation)

Glycolytic products such as pyruvate and lactate induce HIF1alpha accumulation (Feed forward mechanism) pro-apoptotic pathways, (2) contribute to tumour neovascularization via VEGF, VEGF receptors, COX-2, iNOS, (3) regulate cell detachment via down regulation of adhesion molecules such as cadherins, and (4) induce cell migration and invasion through matrix degrading enzymes [57-59] (Table 1, Fig. 1). 
Fig. 1 Regulation of HIF1alpha in normoxic and hypoxic conditions and biological consequences of hypoxia

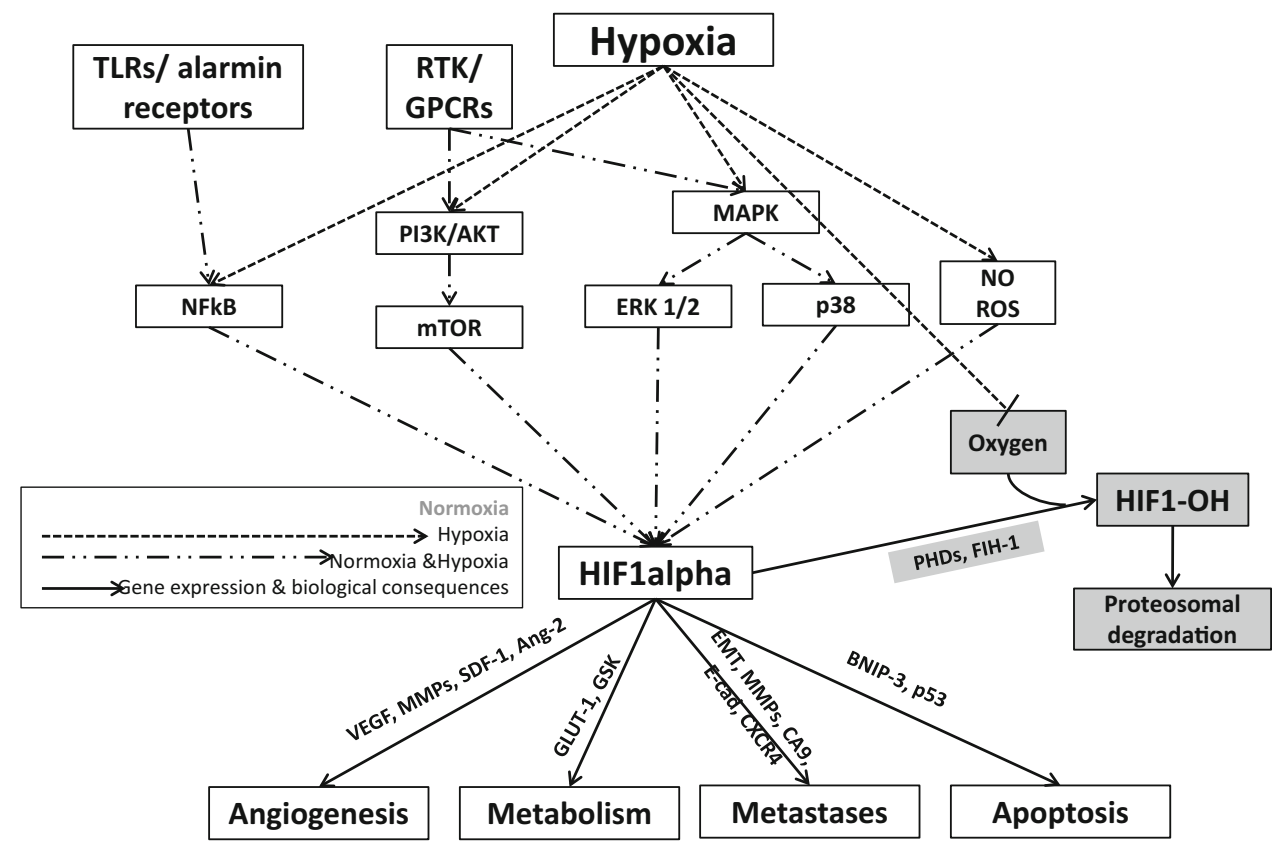

Resistance to chemotherapy and radiotherapy mediated by HIF1 signalling

Drug resistance could potentially occur at the cellular level or secondary to changes in the tumour microenvironment. Tumours have convoluted vasculature which results in proliferating well-nourished cells closer to the functional blood vessels and regions of hypoxic cells located away from the functional blood vessels. Irregular blood flow and large distances between functional blood vessels in solid tumours lead to poor drug distribution, resulting in therapeutic resistance [60].

It is often difficult to discriminate between the effects of hypoxia per se and HIF1, and the literature on the effects of the hypoxic microenvironment and HIF1 on drug efflux and multidrug resistant phenotype [61], for instance, is controversial. Zhao and co-workers recently reported that HIF1alpha suppresses MDR1/P-glycoprotein in gastric cancer by inhibiting miR-27a expression in gastric cancer [62], and in colon cancer cells, inhibition of HIF1 leads to downregulation of $p$-glycoprotein and reversal of multidrug resistant phenotype [63]. In contrast, pronounced hypoxia has minor effect on $p$-glycoprotein expression and activity [64], while acidosis, a feature of the hpoxic micro-environement, increases $p$-glycoprotein activity [65]. In addition, regarding drug efficacy, the hypoxic environment can modify the efficacy of drugs that require molecular oxygen as part of their mechanism of action, e.g., bleomycins $[66,67]$, or are activated by reductases under hypoxia, e.g., evofosfamide, tarloxotinib, tirapazamine, and SN30000 $[68,69]$, and is a barrier to drug delivery generally independent of HIF1 [70]. Hypoxia and HIF1 also confer treatment resistance of cancer cells by inducing cell cycle arrest (quiescence) [71], making drugs that target cycling cells ineffective), and by supporting the highly tumourigenic stem cell niche [72]. In glioblastoma, HIF1alpha+ quiescent stem-like are found to locate within the perinecrotic region and confer higher tumourigenic potential [73]. During severe or prolonged hypoxia, most of the cells undergo programmed cell death. However, some of the tumour cells adjust to environmental stress and survive by avoiding necrosis, inhibition of apoptosis [48, 74, 75], and decreasing senescence of cells [76], mediated by HIFalpha, resulting in an aggressive phenotype and resistance to treatment.

During fractionated radiotherapy, HIF1alpha protects the tumour microvasculature from radiation-induced endothelial apoptosis, via induction of vascular endothelial growth factor (VEGF) and other pro-angiogenic factors and facilitates tumour cell survival by increasing the antioxidant capacity of tumours to counteract radation-induced oxidative stress [21]. Irradiation also induces changes in the tumour microenvironment such as vascular, stromal, and immunological changes which may promote radioresistance and tumour recurrence [77]. These effects eventually lead to the resistance of tumour cells to chemotherapy and radiation.

\section{Measurement of hypoxia}

Knowledge of the hypoxia state enables prediction of treatment outcome and selection of patients for hypoxia modifying treatment. The relative prevalence of diffusion limited hypoxia (DLH), cyclic and perfusional hypoxia in 
human tumours or animal models is not known, and it is predicted that different hypoxia modes require different diagnostic and therapeutic approaches. Several noninvasive techniques (direct or indirect measurements) are available to obtain an absolute or relative value of the oxygenation status of tumours. The various strategies available are described in Table 2 [78-103]. Each of the techniques described interrogates different aspects of the hypoxic microenvironment, and they provide information on hypoxia at different locations: Oxygen electrodes and OxyLite sampling predominantly measure interstitial hypoxia. PET, SPECT, and extrinsic markers report on intracellular hypoxia and PET/SPECT images quantify data on a macroscopic scale in tumour regions. Blood oxygen level-dependent (BOLD)-MRI and Oxy-R fraction allow assessment of blood oxygenation, while indirect methods that report on hypoxia-induced molecular events (e.g., GLUT1, CA9 expression) rather than hypoxia itself have also been utilised as markers of tumour oxygenation.

\section{MRI methods}

These include MR-based gradient-recalled echo techniques, electron paramagnetic resonance, and MR spectroscopy. MRI methods for interrogating tumour oxygenation are attractive since MRI scanners are widely available and they avoid the complication of short-lived radioactivity.

\section{Blood oxygen level dependent (BOLD)-MRI}

The most facile contrast mechanism, which depends on blood oxygenation-blood oxygen level dependent (BOLD) MRI-avoids the need for reporter molecules by imaging differences between diamagnetic oxy-haemoglobin and paramagnetic deoxy-haemoglobin. The presence of deoxy-haemoglobin in a blood vessel causes susceptibility differences between vessel and its surrounding tissue resulting in a decrease in $\mathrm{T} 2 *$ leading to darkening in tissues containing the vessel in a $\mathrm{T} 2 *$-weighted imaging protocol. A limitation is that it is also sensitive to changes in $\mathrm{Hb}$ concentration (due to alterations in vascular volume and flow as well as interconversion of oxy- and deoxyhaemoglobin). Therefore, this technique provides qualitative assessment of changes in oxygenation rather than quantitative measurements. The technique is widely used for functional brain mapping [104, 105], where it is thought to primarily reflect changes in flow.

Baudelet and Gallez have rigorously investigated correlations between $\mathrm{pO}_{2}$ estimated using fibre optic probes and BOLD signal changes and have found general correlations, but a given BOLD response may reflect vastly different changes in $\mathrm{pO}_{2}$ [102]. BOLD MRI has the advantage of both high spatial and temporal resolution and it can be repeated as needed; however, it can be susceptible to subtle motion artefacts [106]. Rijpkema et al. used BOLD to evaluate patients during the ARCON trial for head and neck cancer and found significant changes in T2*-weighted MRI contrast accompanying hyperoxic gas breathing [107]. No accompanying changes were observed by traditional T1weighted gadolinium dynamic contrast-enhanced MRI. Preliminary analysis of 11 women being treated with chemotherapy for locally advanced breast cancer showed a significantly different BOLD response to breathing oxygen before the course of chemotherapy for tumours of women with good therapeutic outcome versus those with poor response. Indeed, three women with complete pathologic response showed a signal change greater than $7 \%$, whereas those with poor outcome showed less than 3\% [108]. It is arguable whether the differential response reflects perfusion or oxygenation, but traditional dynamic contrast-enhanced MRI failed to provide similar discrimination.

The biologic sequelae of hypoxia are also amenable to imaging. Prolonged hypoxia can lead to increased lactate in tissues and ${ }^{1} \mathrm{H}$ MRI can be used to image lactate $[109,110]$. Furthermore, alteration of the redox state of nonprotein thiols, such as glutathione, adenine nucleotide redox state, NADH or NADPH in hypoxic cells can lead to accumulation of radiopharmaceuticals in hypoxia. All of these tests measure downstream consequences of hypoxia and often do not instantly return to normal values after an adequate $\mathrm{O}_{2}$ supply has been established. For more information, the reader is referred to a recent review that addressed the role of functional MRI (fMRI) methods to assess tumour oxygenation for predicting outcome [111].

\section{PET imaging of hypoxia}

Positron emission tomography (PET) has inherent advantages for studying hypoxia, as it can employ radiotracer probes that directly report on cellular oxygen levels, and not via hypoxia-mediated changes in phenotype, thereby permitting the non-invasive and three-dimensional assessment of intratumour oxygen levels in a more direct manner [112]. In contrast to histologic characterisation, PET can monitor whole tumours although at low spatial resolution [113]. PET has very high sensitivity and specificity compared to MR imaging and it enables the identification of regional hypoxia in vivo in preclinical and clinical settings [103].

PET tracers for hypoxia imaging and their mechanisms of action

The criteria for development of radiotracer probes includes improving relative tumour uptake by using isotopes with 
Table 2 Methods of hypoxia assessment

\begin{tabular}{|c|c|c|c|c|}
\hline Technique & $\begin{array}{l}\text { Oxygen } \\
\text { sensing } \\
\text { range }\left(\mathrm{pO}_{2}\right)\end{array}$ & Mechanism & Advantages & Disadvantages \\
\hline \multicolumn{5}{|l|}{ Direct measurements } \\
\hline $\begin{array}{l}\text { Oxygen electrodes } \\
\text { (Eppendorf probes) } \\
{[77-82]}\end{array}$ & 0-100 mmHg & $\begin{array}{l}\text { Allows direct point measurements } \\
\text { of the partial oxygen pressure } \\
\text { A polarographic needle is inserted } \\
\text { in a tumour and several } \\
\text { measurements along a track are } \\
\text { obtained }\end{array}$ & $\begin{array}{l}\text { Strong correlation with clinical } \\
\text { outcome in patients with } \mathrm{HN} \text {, } \\
\text { cervical, or prostate cancer }\end{array}$ & $\begin{array}{l}\text { Invasive, technically } \\
\text { demanding } \\
\text { Suitable only for accessible } \\
\text { tumours } \\
\text { Results are operator dependent } \\
\text { No longer commercially } \\
\text { available } \\
\text { Risks modifying the oxygen } \\
\text { concentration }\end{array}$ \\
\hline $\begin{array}{l}\text { OxyLite (fibre optic } \\
\text { technique) [84] }\end{array}$ & & $\begin{array}{l}\text { Allows continuous measurement } \\
\text { at a single spot in a tumour, } \\
\text { whereby changes in } \\
\text { oxygenation within a short } \\
\text { period of time (several hours) } \\
\text { can be obtained }\end{array}$ & Promising preclinical studies & $\begin{array}{l}\text { Invasive } \\
\text { Never approved for clinical use }\end{array}$ \\
\hline \multicolumn{5}{|l|}{ Indirect measurements } \\
\hline $\begin{array}{l}\text { Exogenous biomarkers } \\
\text { Bioreductive } \\
\text { Nitroimidazole drugs } \\
\text { Pimonidazole [85] and } \\
\text { EF5 [86] Fluorescent } \\
\text { Pimonidazole }[87,88]\end{array}$ & $<1 \mathrm{mmHg}$ & $\begin{array}{l}\text { Bioreduction and trapping under } \\
\text { hypoxia. Predominantly } \\
\text { derivatives of nitroimidazole } \\
\text { compounds } \\
\text { These can be chemically bound to } \\
\text { an immune-reactive side chain, } \\
\text { or fluorescent marker, for IHC } \\
\text { detection of hypoxia } \\
\text { Estimates the distance from cells } \\
\text { to a vessel (radioresistant cells } \\
\text { are further away from vessels) }\end{array}$ & $\begin{array}{l}\text { Can be used with biopsies or } \\
\text { surgical specimens } \\
\text { Objective quantitation of } \\
\text { hypoxia using } \\
\text { immunohistochemistry or } \\
\text { flow cytometry or fluorescent } \\
\text { probes } \\
\text { Provides information about the } \\
\text { microregional distribution of } \\
\text { hypoxia Indicate biologically } \\
\text { relevant hypoxia because of } \\
\text { its radioresistance }\end{array}$ & $\begin{array}{l}\text { Invasive (requires biopsy or } \\
\text { resection) } \\
\text { Drug administered in advance } \\
\text { Binding of drug dependent on } \\
\text { the presence of tissue } \\
\text { reductases } \\
\text { Careful tumour sampling } \\
\text { necessary to account for } \\
\text { heterogeneity }\end{array}$ \\
\hline $\begin{array}{l}\text { Endogenous biomarkers } \\
\text { [89-97] }\end{array}$ & $<10 \mathrm{mmHg}$ & $\begin{array}{l}\text { Consist of proteins that are } \\
\text { predominantly under control of } \\
\text { HIF: HIF1, HIF2, CA9, GLUT- } \\
\text { 1, and vascular endothelial } \\
\text { growth factor (VEGF) } \\
\text { High expression of these is } \\
\text { correlated with treatment failure } \\
\text { in various cancers }\end{array}$ & $\begin{array}{l}\text { Can be used with archival } \\
\text { biopsies or surgical } \\
\text { specimens without the need } \\
\text { for prior drug administration } \\
\text { Provides information about the } \\
\text { microregional distribution of } \\
\text { hypoxia }\end{array}$ & $\begin{array}{l}\text { Invasive (requires biopsy or } \\
\text { resection) } \\
\text { Gene and protein expression } \\
\text { influenced by hypoxia- } \\
\text { independent factors } \\
\text { Careful tumour sampling } \\
\text { necessary to account for } \\
\text { heterogeneity }\end{array}$ \\
\hline $\begin{array}{l}\text { MRI Blood oxygen- } \\
\text { dependent level (BOLD) } \\
\text { and tissue oxygen level- } \\
\text { dependent (TOLD) } \\
\text { magnetic resonance } \\
\text { imaging (MRI) [102] }\end{array}$ & $\begin{array}{l}\text { Poor correlation } \\
\text { with } \\
\text { absolution } \\
\mathrm{pO}_{2} \\
\text { levels(BOLD) }\end{array}$ & $\begin{array}{l}\text { BOLD: paramagnetic } \\
\text { deoxyhemoglobin molecules } \\
\text { in red blood cells cause magnetic } \\
\text { susceptibility, which increases } \\
\text { the local transverse MRI } \\
\text { relaxation rate (R2; units } \mathrm{ms}^{-1} \text { ) }\end{array}$ & $\begin{array}{l}\text { Noninvasive } \\
\text { Assessment of the entire } \\
\text { tumour volume } \\
\text { Spatial mapping of hypoxia } \\
\text { Serial assessment over time } \\
\text { Better spatial and temporal } \\
\text { resolution of TH than PET } \\
\text { provides }\end{array}$ & $\begin{array}{l}\text { Indirect measure of hypoxia } \\
\text { (deoxyhemoglobin } \\
\text { concentration) } \\
\text { Strong dependence on perfusion } \\
\text { Susceptible to motion artefacts } \\
\text { (BOLD), or absolute value is } \\
\text { influenced by adequacy of } \\
\text { oxygen saturation during } \\
\text { inhalation (Oxy-R fraction) }\end{array}$ \\
\hline $\begin{array}{l}\text { Oxy-R fraction derived } \\
\text { from oxygen enhanced } \\
\text { MRI [98] }\end{array}$ & $\begin{array}{l}\text { Probably } \\
0-100 \mathrm{mmHg}\end{array}$ & $\begin{array}{l}\text { Oxy-R fraction: dissolved oxygen } \\
\text { in blood plasma and/or } \\
\text { interstitial space when } \\
\text { hyperoxic gas is breathed } \\
\text { increases longitudinal MRI } \\
\text { relaxation rate }\left(\mathrm{R} 1 \text {; units } \mathrm{s}^{-1} \text { ) in }\right. \\
\text { well perfused tissue }\end{array}$ & $\begin{array}{l}\text { Quantifies the spatial } \\
\text { distribution and extent of } \\
\text { tumour oxygen delivery } \\
\text { in vivo } \\
\text { Can be readily quantified on } \\
\text { clinical MRI scanners }\end{array}$ & $\begin{array}{l}\text { Awaiting oncology clinical } \\
\text { translation }\end{array}$ \\
\hline $\begin{array}{l}\text { MR Oximetry Based on } \\
\text { perfluorocarbons (PFCs) } \\
\text { [99-101] }\end{array}$ & $\begin{array}{l}\text { Probably } \\
\text { 0-100 mmHg }\end{array}$ & $\begin{array}{l}\text { Sequestered in the } \\
\text { reticuloendothelial system } \\
\text { (liver, spleen, bone marrow) due } \\
\text { to macrophage accumulation }\end{array}$ & $\begin{array}{l}\text { Correlates with pO2 } \\
\text { Long half-life enables chronic } \\
\text { hypoxia evaluation }\end{array}$ & $\begin{array}{l}\text { Susceptible to flow artefacts } \\
\text { Doses for imaging causes } \\
\text { hepatosplenomegaly }\end{array}$ \\
\hline
\end{tabular}


Table 2 continued

\begin{tabular}{|c|c|c|c|c|}
\hline Technique & $\begin{array}{l}\text { Oxygen } \\
\text { sensing } \\
\text { range }\left(\mathrm{pO}_{2}\right)\end{array}$ & Mechanism & Advantages & Disadvantages \\
\hline $\begin{array}{l}\text { PET 2-Nitroimidazole } \\
{\left[{ }^{18} \mathrm{~F}\right] \text { labelled tracers }} \\
\text { (MISO, FMISO, EF5, } \\
\text { FAZA, and HX4) Other } \\
\text { tracers }\left(\left[{ }^{60} \mathrm{Cu}\right] \mathrm{Cu} \text {-ATSM) }\right. \\
{[103]}\end{array}$ & $<1 \mathrm{mmHg}$ & Redox-based trapping & $\begin{array}{l}\text { Noninvasive } \\
\text { Assessment of the entire } \\
\text { tumour volume } \\
\text { Spatial mapping of hypoxia } \\
\text { Serial assessment over time }\end{array}$ & $\begin{array}{l}\text { No consensus about preferred } \\
\text { tracer } \\
\text { False-positive results from } \\
\text { unbound tracer } \\
\text { Uptake in bladder and other } \\
\text { normal tissues } \\
\text { Limited spatial resolution } \\
\text { Low tumour-background ratio }\end{array}$ \\
\hline
\end{tabular}

longer half-lives and ensuring rapid clearance of the parent compound from systemic circulation and normoxic tissue (hydrophilic compounds), while being sufficiently lipophilic to enter cells and allow uniform tissue distribution. The charcteristics of an ideal hypoxic tracer include: retention in low partial oxygen pressure $\left(\mathrm{pO}_{2}\right)$ regions (hypoxia specific), pharmacokinetic profile and tissue distribution independent of confounding factors such as blood flow/tissue perfusion or $\mathrm{pH}$, high stability, suitable tissue kinetics to enable imaging in a specified time frame, ease of synthesis, favourable dosimetry profile, reproducibility and effectiveness in multiple tumour types .

Radionuclide detection of hypoxia in tumours was first reported in 1981 with $\left[{ }^{14} \mathrm{C}\right]$ misonidazole autoradiography [114]. Subsequently, two main tracer classes have been developed to specifically study regional tumour hypoxia with PET: $\left[{ }^{18} \mathrm{~F}\right]$ labelled nitroimidazoles and $\mathrm{Cu}$-labelled diacetyl-bis(N4-methylthiosemicarbazone) analogues [112]. Multiple PET tracers suitable for the detection of hypoxia have been developed, validated and shown to exhibit different characteristics; some of these are discussed in Table 3 [115-127]. The first $\left[{ }^{18} \mathrm{~F}\right]$ labelled drug to be clinically tested was fluoromisonidazole (FMISO) [128] and it remains the most extensively tested agent $[129,130]$.

\section{$\left[{ }^{18}\right.$ F $]$ Nitroimidazoles}

2-Nitroimidazole compounds were originally developed as hypoxic cell radiosensitisers and were introduced as hypoxia markers in the 1970s (Fig. 2) [115]. Nitroimidazoles enter cells by passive diffusion and subsequently undergo reduction forming reactive intermediate species. Hypoxic conditions cause further reduction of the nitroanion radical, which is irreversibly trapped in the cell when the oxygen tension is less than $10 \mathrm{mmHg}$ [129]. The reduction of nitroimidazoles requires the presence of ubiquitously expressed tissue reductases, which enables these compounds to accumulate within viable hypoxic cells, but not apoptotic or necrotic cells [130-132]. Under normoxic conditions, nitro-anion radical is re-oxidised into the parent compound, which can diffuse out of the cell. The mechanism of of $\left[{ }^{18} \mathrm{~F}\right] \mathrm{MISO}$ intracellular trapping is shown in Fig. 3 [133]. Therefore, hypoxic tissues can be delineated as an area of high tracer uptake after allowing a sufficient period of time for the nonspecific tracer to be excreted from the cells [134, 135].

FMISO uptake was closely correlated with pimonidazole immunohistochemistry and has been found to reflect hypoxia in head-and-neck cancer [136-146], glioma [147-152], colorectal cancer [153], breast cancer [154], lung cancer $[155,156]$, and renal cell carcinoma $[157,158]$.

In view of FMISO's slow plasma clearance, FMISO imaging usually requires an interval of longer than $2 \mathrm{~h}$ (ideally $4 \mathrm{~h}$ ) after administration to obtain good contrast [159] with a hypoxia threshold in general defined as SUVmax of 1.5 or tumour:muscle ratio of 1.4 [103]. Although its biodistribution properties do not result in high-contrast images, the 2-h image unambiguously reflects regional $\mathrm{pO}_{2}$ in the range where it is clinically significant. However, due to perceived concerns regarding FMISO stability in vivo [160], metabolite formation, slow clearance properties [129], and failure to achieve image intensities in humans comparable to what had been achieved in animal models, alternative hypoxia PET tracers with different clearance and hydrophilicity characteristics have been developed in an attempt to overcome these limitations. These include fluoroazomycin arabinoside (FAZA), fluoroerythronitroimidazole (FETNIM), fluoroetanidazole (Fig. 4), and fluorinated etanidazole derivatives (EF3, EF5), HX4 [161-163].

\section{$\left[{ }^{18}\right.$ F]Fluoroazomycin-arabinofuranoside (FAZA)}

$\left[{ }^{18} \mathrm{~F}\right]$ Fluoroazomycin-arabinofuranoside (FAZA) is more hydrophilic than FMISO. Consequently, it has faster 
Table 3 Salient characteristics of hypoxic radiotracers

\begin{tabular}{|c|c|c|c|}
\hline Class & Mechanism of action & Advantages & Limitations \\
\hline \multicolumn{4}{|l|}{ Nitroimidazoles } \\
\hline $\begin{array}{l}{\left[{ }^{18} \mathrm{~F}\right] \mathrm{FMISO}} \\
{[115]}\end{array}$ & $\begin{array}{l}\text { Nitroimidazole compounds are used for } \\
\text { imaging oxygen-deprived hypoxic } \\
\text { cells, based on the intracellular } \\
\text { accumulation of radicals formed after } \\
\text { the reduction by ubiquitous } \\
\text { nitroreductases. Under oxygenated } \\
\text { conditions, in contrast, the nitro } \\
\text { radical anions of the compounds are } \\
\text { reoxidized and cleared from cells by } \\
\text { back-diffusion }\end{array}$ & $\begin{array}{l}\text { Lipophilicity ensures facile cell- } \\
\text { membrane penetration and diffusion } \\
\text { into tissue } \\
\text { FMISO uptake correlates with } \\
\text { pimonidazole immunohistochemistry } \\
\text { in various cancers }\end{array}$ & $\begin{array}{l}\text { Only available for research purposes. } \\
\text { Modest hypoxic-to-normoxic tissue } \\
\text { ratios (due to limited clearance) and } \\
\text { limited hypoxic contrast potentially } \\
\text { impedes visual detection of hypoxic } \\
\text { regions: limited diagnostic utility in } \\
\text { routine practice } \\
\text { Slow tracer accumulation and low } \\
\text { tumour-to-background contrast } \\
\text { requires delayed scans to allow } \\
\text { background activity to decrease } \\
{[116,117]}\end{array}$ \\
\hline $\begin{array}{l}{\left[{ }^{18} \mathrm{~F}\right] \mathrm{FAZA}} \\
{[118]}\end{array}$ & & $\begin{array}{l}\text { More hydrophilic: faster clearance } \\
\text { kinetics, resulting in improved } \\
\text { hypoxia-to-normoxia contrast }\end{array}$ & Not widely available \\
\hline $\begin{array}{c}{\left[{ }^{18} \mathrm{~F}\right] \mathrm{EF} 5} \\
{[119]}\end{array}$ & & $\begin{array}{l}\text { Greater cell membrane permeability and } \\
\text { slower blood clearance leads to } \\
\text { improved rates of tumour uptake and } \\
\text { homogeneity of tracer distribution }\end{array}$ & $\begin{array}{l}\text { Complex labelling chemistry and slow } \\
\text { elimination due to higher lipophilicity }\end{array}$ \\
\hline $\begin{array}{l}\left.{ }^{18} \mathrm{~F}\right] \mathrm{HX} 4 \\
{[120]}\end{array}$ & & $\begin{array}{l}\text { Hydrophilic } \\
\text { Shorter acquisition times }\end{array}$ & No advantage over FMISO \\
\hline $\begin{array}{c}{\left[{ }^{18} \mathrm{~F}\right] \mathrm{FETNIM}} \\
{[121,122]}\end{array}$ & & $\begin{array}{l}\text { Rapid renal clearance and low liver } \\
\text { uptake }\end{array}$ & $\begin{array}{l}\text { No advantage over FMISO } \\
\text { Not widely available }\end{array}$ \\
\hline $\begin{array}{l}{\left[{ }^{18} \mathrm{~F}\right] \mathrm{RP}-170} \\
\quad[123]\end{array}$ & & $\begin{array}{l}\text { Shorter acquisition times, } \\
\text { Improved hypoxic contrast }\end{array}$ & Not widely available \\
\hline $\begin{array}{l}\text { SR4554 } \\
\quad[124,127]\end{array}$ & & $\begin{array}{l}\text { MR spectroscopy method analogous to } \\
\text { FMISO but requiring measurement of } \\
\text { elimination kinetics }\end{array}$ & Not widely available \\
\hline \multicolumn{4}{|c|}{ Copper-diacetyl- bis(N4-methylthiosemicarbazone) (Cu-ATSM) } \\
\hline $\begin{array}{l}\text { Cu-ATSM } \\
{[124,125]}\end{array}$ & $\begin{array}{l}\text { The hypoxic specificity of Cu-ATSM is } \\
\text { thought to be partly imparted by the } \\
\text { intracellular reduction of } \mathrm{Cu}(\mathrm{II}) \text { to } \\
\mathrm{Cu}(\mathrm{I}) \text {. Under hypoxic conditions, the } \\
\text { unstable } \mathrm{Cu}(\mathrm{I}) \text { - } \mathrm{ATSM} \text { complex may } \\
\text { further dissociate into } \mathrm{Cu}(\mathrm{I}) \text { and } \\
\text { ATSM, leading to the intracellular } \\
\text { trapping of the } \mathrm{Cu}(\mathrm{I}) \text { ion }\end{array}$ & $\begin{array}{l}\text { Simpler synthesis/radiolabelling } \\
\text { methodology } \\
\text { Reveals 'hypoxic' tissue within } \\
10-15 \text { min after IV administration } \\
\text { mainly due to its rapid tracer kinetics } \\
\text { Cu-ATSM uptake might better } \\
\text { represent a general prognosticator of } \\
\text { poor treatment response }\end{array}$ & $\begin{array}{l}\text { Limited availability of } \mathrm{Cu} \text { isotopes, } \\
\text { Only produced at a few research sites }\end{array}$ \\
\hline
\end{tabular}

clearance kinetics, resulting in improved tumour-to-reference tissue ratios, and thus hypoxia-to-normoxia contrast. Head-to-head comparisons between FAZA, $\left[{ }^{124}\right.$ I]IAZA, and FMISO in preclinical animal studies imaged at $3 \mathrm{~h}$ after injection demonstrated faster vascular clearance of FAZA, resulting in an increased tumour-toblood ratio (5.19) relative to that of $\left[{ }^{18} \mathrm{~F}\right]$ fluoromisonidazole (3.98). More recently, clinical studies have successfully evaluated the feasibility of FAZA for imaging hypoxia in gliomas [118], lymphomas [118], lung [164, 165], head-and-neck [118, 166-168], cervical [169], and rectal tumours [170], and the results have been shown to compare favourably with equivalent FMISO data, especially as improved hypoxic-normoxic contrast was obtained at earlier time points. High FAZA tumourto-reference tissue values have been associated with reduced disease-free survival and have shown prognostic potential in the detection of hypoxia in head-and-neck patients [167]. Due to the higher tumour-to-reference tissue ratios in comparison with FMISO, FAZA is gaining popularity for PET imaging of tumour hypoxia. Despite the fact that FAZA is not widely available at present, increasing research demand may persuade more sites to produce it. 
<smiles>O=[N+]([O-])c1nccn1CC(O)CF</smiles>

$\left[{ }^{18} \mathrm{~F}\right] \mathrm{FMISO}$<smiles>O=[N+]([O-])c1nccn1CC(O)C(O)C[18F]</smiles>

$\left[{ }^{18}\right.$ F]FETNIM<smiles>O=C(Cn1ccnc1[N+](=O)[O-])NCC(F)(F)C(F)(F)C(F)(F)F</smiles>

$\left[{ }^{18} \mathrm{~F}\right] \mathrm{EF} 5$<smiles>O=[N+]([O-])c1nccn1Cc1cn(C(CO)C[18F])nn1</smiles>

$\left[{ }^{18} \mathrm{~F}\right] \mathrm{HX}-4$<smiles>O=[N+]([O-])c1nccn1[C@@H]1O[C@H](C[18F])[C@@H](O)[C@H]1O</smiles>

$\left[{ }^{18} \mathrm{~F}\right] \mathrm{FAZA}$<smiles>O=[N+]([O-])c1nccn1COC(CO)C[18F]</smiles><smiles>O=C(Cn1ccnc1[N+](=O)[O-])NCC[18F]</smiles>

$\left[{ }^{18}\right.$ F]FETA

Fig. 2 Structures of clinically used $\left[{ }^{18} \mathrm{~F}\right]$-labelled nitroimidazole compounds

Fig. 3 Schematic representation of FMISO uptake in hypoxic conditions

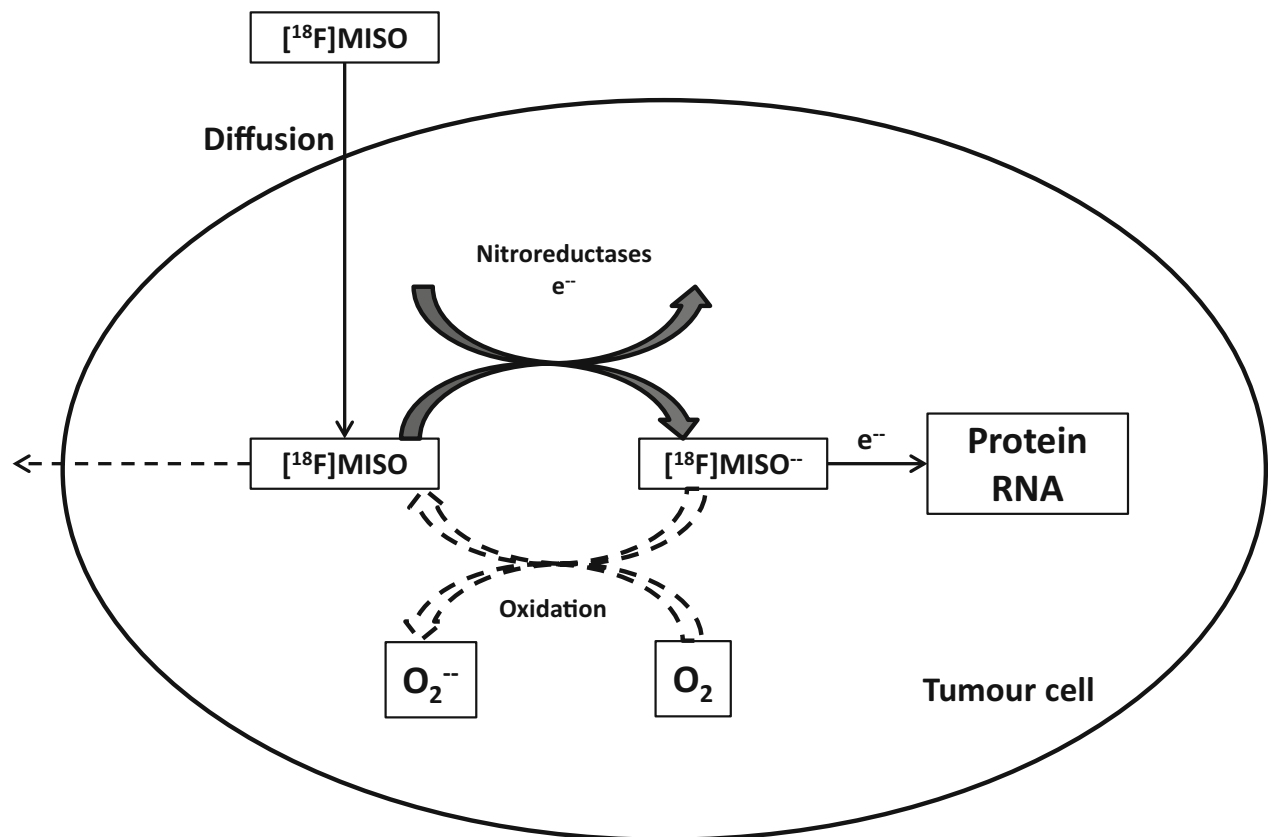

\section{Next-generation tracers}

\section{$\left.{ }^{18} \mathrm{~F}\right] 2$-(2-nitro-1H-imidazol-1-yl)-N-(2,2,3,3,3- Pentafluoropropyl)-acetamide (EF5)}

The nitroimidazole EF5 has been extensively used for ex vivo immunohistochemical detection of bioreduced adducts, which indicate regions of tumour hypoxia. However, $\quad\left[{ }^{18} \mathrm{~F}\right] 2-(2-n i t r o-1 H-i m i d a z o l-1-y l)-N-(2,2,3,3,3-$ pentafluoropropyl)-acetamide (EF5), first investigated as a hypoxia PET tracer in 2001 [171], has only recently appeared in the clinical setting. In contrast to many of the secondgeneration hypoxia tracers, EF5 is highly lipophilic, resulting in greater cell membrane permeability and slower blood clearance [119], thus improving rates of tumour uptake and homogeneity of tracer distribution. The main drawback of
EF5 is the complex labelling chemistry in comparison to the simple nucleophilic displacement reactions used for the mono-fluorinated 2-nitroimidazoles [171].

\section{$\left[{ }^{18}\right.$ F]3-fluoro-2-(4-((2-nitro-1H-imidazol-1- yl)Methyl)-1H-1,2,3-triazol-1-yl)propan-1-ol (HX4)}

$\left[{ }^{18} \mathrm{~F}\right] 3$-fluoro-2-(4-((2-nitro-1H-imidazol-1-yl)methyl)-1H1,2,3-triazol-1-yl)propan-1-ol (HX4), a next-generation 2-nitroimidazole tracer contains a 1,2,3-anti-triazole moiety (as a synthetic convenience) rendering it more hydrophilic than FMISO, specifically designed to maximize pharmacokinetic and clearance properties. Initial studies in humans demonstrate rapid renal clearance and urinary excretion of $\mathrm{HX} 4$, with a favourable dosimetry profile similar to that of FMISO [120]. 


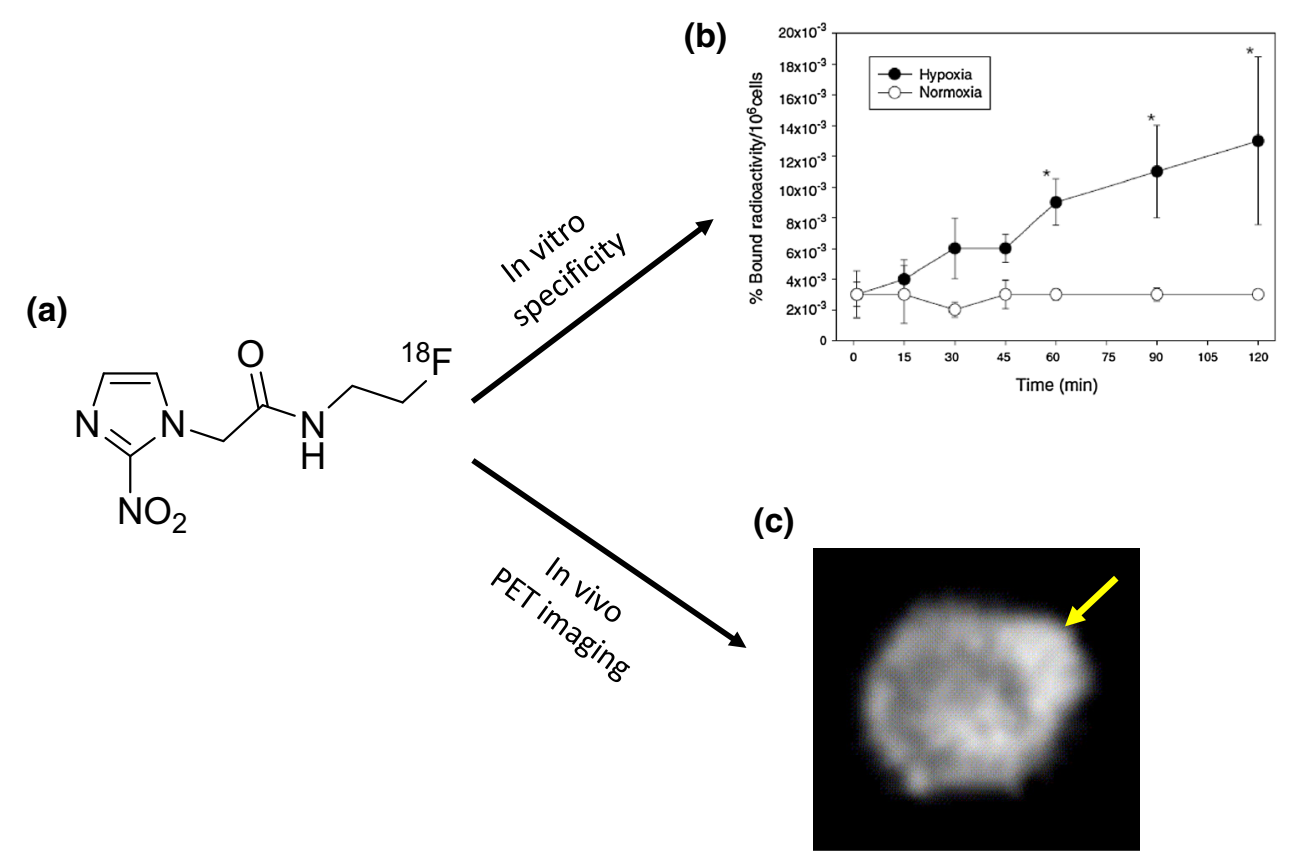

Fig. 4 Hypoxia imaging with radiolabelled 2-nitroimidazole. a Chemical structure of $\left[{ }^{18} \mathrm{~F}\right]$ fluoroetanidazole. The nitro moiety is necessary for hypoxia selective retention. b Cellular uptake of $\left[{ }^{18} \mathrm{~F}\right]$ fluoroetanidazole in RIF-1 cell line culture grown under normoxia or hypoxia (nitrogen gas). The amount of radioactivity bound to cells was counted. c Imaging of $\left[{ }^{18} \mathrm{~F}\right]$ fluoroetanidazole by

Preclinical studies validated that the tracer uptake was indeed oxygen-dependent though tumour-to-background ratios appeared similar to those reported for FMISO in studies using the same tumour model [172]; thus, it remains to be seen if $\mathrm{HX} 4$ provides any significant advantage over FMISO in a clinical setting. A phase I study of 6 patients (4 non-small-cell lung carcinoma, 1 thymus carcinoma, and 1 colon carcinoma) has shown a median tumour-to-muscle ratio of 1.40 at $120 \mathrm{~min}$ after injection, although no attempt was made to determine the optimal imaging time points [120]. In head-and-neck tumours, HX4 produced tumour-to-reference tissue values similar to FMISO at relatively early time points post injection, indicating the potential advantage of shorter acquisition times [173]. A more recent study in non-small cell lung cancer (NSCLC) patients [174] suggested that later scan times $(2-4 \mathrm{~h}$ p.i.) can further enhance the hypoxic-to-normoxic signal.

\section{$\left[{ }^{18}\right.$ F]Fluoroerythronitromidazole (FETNIM)}

The hydrophilic nature of $\left[{ }^{18} \mathrm{~F}\right]$ Fluoroerythronitromidazole (FETNIM) accounts for its rapid renal clearance and low liver uptake, compared with FMISO. This also could explain the positive correlation between tumour blood flow and initial tumour FETNIM uptake [121]. Recent
PET showing tracer localisation in HT1080 (subclone 1-3C) xenograft. A $0.5-\mathrm{mm}$ transverse slice of the 30-60 min image acquired in a small animal PET scanner is shown. Arrow, tumour. Courtesy of EOA Published in Br J Cancer 2004 (Barthel et al.) (Color figure online)

clinical studies in head-and-neck [121, 175, 176], lung [177, 178], cervical cancer [179], and oesophageal cancer [180] showed that high tissue uptake of FETNIM was indicative of reduced progression-free and overall survival. However, as with $\mathrm{HX} 4$, it is not clear whether the use of this tracer presents any advantages over FMISO imaging protocols. Clinical studies with FETNIM have been mainly carried out at the University of Turku, Finland.

\section{$\left[{ }^{18}\right.$ F]1-(2-1-(1H-methyl)ethoxy)-methyl-2- nitroimidazole (RP-170)}

1-(2-1-(1H-methyl)ethoxy)-methyl-2-nitroimidazole was developed as a 2-nitroimidazole-based hypoxic radiosensitiser, which has also been labelled with fluorine-18 ( $\left.\left[{ }^{18} \mathrm{~F}\right] \mathrm{RP}-170\right)$. The hypoxic selectivity of RP-170 was demonstrated in glioma patients on the basis of significant correlations between uptake, oxygen tension measurements, and HIF1alpha immunostaining [123]. Studies in brain [123, 181] and lung [182] tumours indicated higher SUV (calculated at $1 \mathrm{~h}$ post injection), for hypoxic than normal tissues. The shorter interval before scanning, combined with improved hypoxic contrast compared with FMISO, could make it attractive for clinical imaging. 


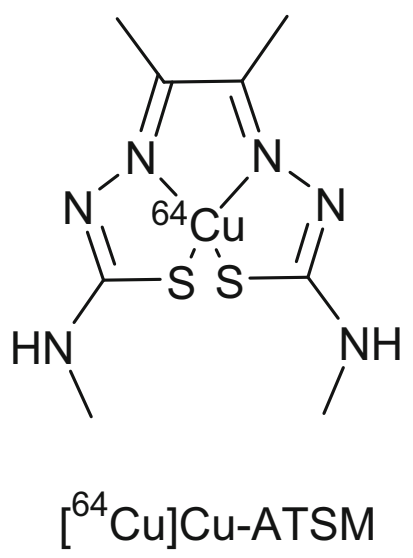

Fig. 5 Structure of $\left[{ }^{64} \mathrm{Cu}\right] \mathrm{Cu}-\mathrm{ATSM}$

\section{Copper (Cu)-diacetyl-bis (N4- methylthiosemicarbazone) (Cu-ATSM)}

An alternative class of agents for the study of hypoxia with PET that has been intensively investigated in both preclinical and clinical studies is the complex of $\mathrm{Cu}$ with diacetyl-bis(N4-methylthiosemicarbazone)

(ATSM) ligands, among which ATSM is the prototype (Fig. 5). The potential of these agents for hypoxia imaging was first reported by Fujibayashi et al. [124]. Copper (Cu)-diacetyl- bis (N4-methylthiosemicarbazone) (Cu-ATSM) is a hypoxic marker that is selectively retained in hypoxic tissues. Cu-ATSM rapidly diffuses into the cells due to its high membrane permeability and low redox potential, secondary to its lipophilicity and low molecular weight. After cellular entry, $\mathrm{Cu}(\mathrm{II})-\mathrm{ATSM}$ is reduced to an unstable $\mathrm{Cu}(\mathrm{I})$-ATSM species, which further dissociates into the metal complex $\mathrm{Cu}(\mathrm{I})$, and ATSM, thus irreversibly trapping the $\mathrm{Cu}(\mathrm{I})$ within the cellular copper metabolic processes (Fig. 6) [183]. In normoxic conditions, the [Cu(I)-ATSM] can be re-oxidised to its parent compound, allowing efflux from the cell [184]. One of the advantages of Cu-ATSM is that it can reveal molecular contrast within 10-15 min post injection mainly due to its rapid tracer kinetics [125, 185].

However, it has been observed that high uptake in tumours may only partly be a direct consequence of hypoxia [185]. Nevertheless, extremely high-contrast images of $\mathrm{Cu}$-ATSM have been obtained in a variety of tumour sites [186]. The lack of correlation between $\mathrm{Cu}$ ATSM distribution and immunohistochemistry hypoxia markers casted some doubt on the hypoxia selectivity of $\mathrm{Cu}$-ATSM [187]. The suggested reason for the low correlation between $\mathrm{Cu}$-ATSM uptake and hypoxic distribution, in some tumours, was the differing redox status of the tumour types. This has been further seen in pre-clinical
Fig. 6 Schematic representation of proposed mechanism of $\left[{ }^{64} \mathrm{Cu}\right] \mathrm{Cu}-\mathrm{ATSM}$

\section{Cu(II)-ATSM}

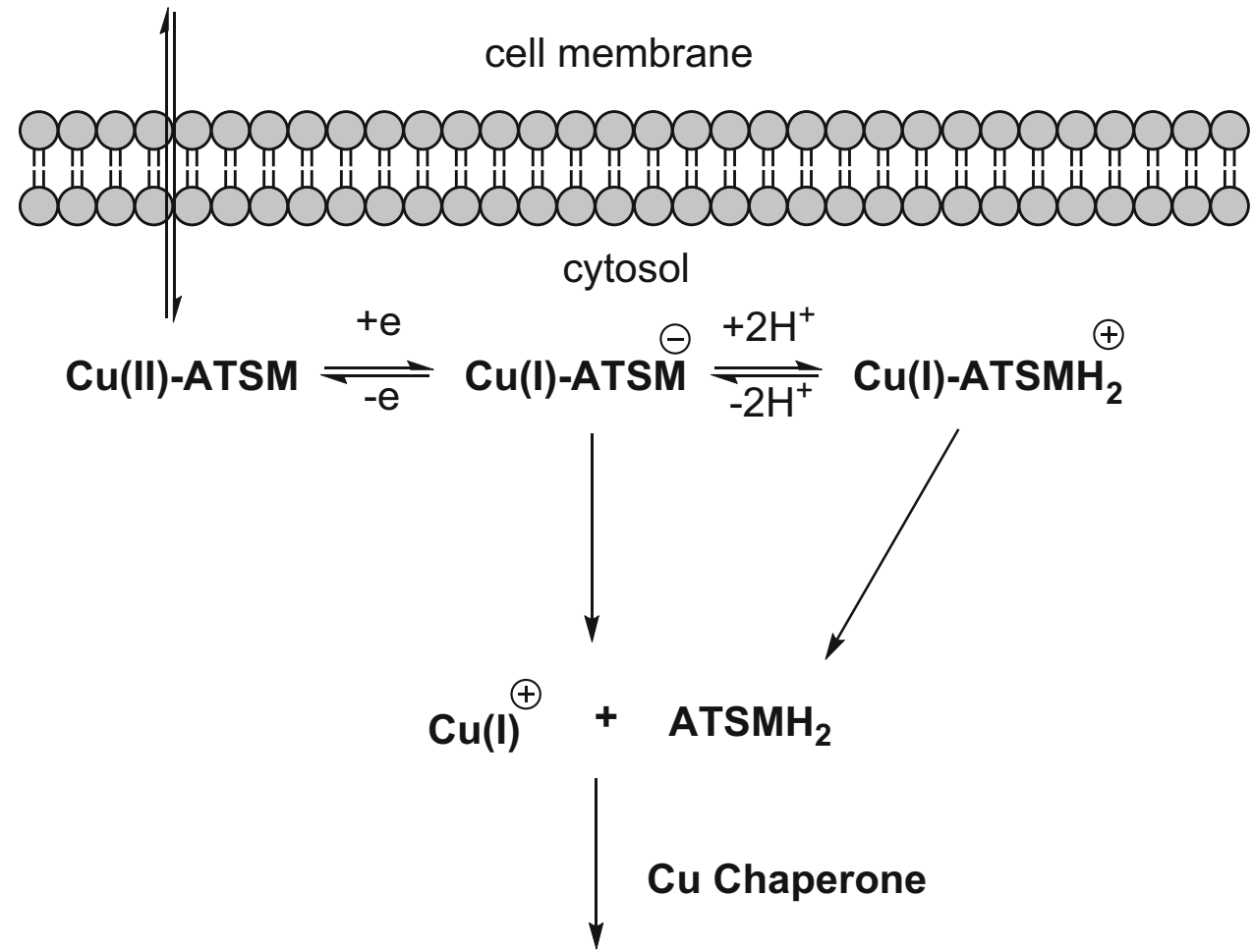

Subsequent $\mathrm{Cu}$ metabolism 
experiments, where it was demonstrated that in the cell lines tested, $\left[{ }^{64} \mathrm{Cu}\right] \mathrm{Cu}$-ATSM and $\left[{ }^{64} \mathrm{Cu}\right] \mathrm{Cu}$-acetate had almost identical uptake in vivo over $2-16 \mathrm{~h}$, post injection. However, up to $1 \mathrm{~h}$ post injection, $\left[{ }^{64} \mathrm{Cu}\right] \mathrm{Cu}$-acetate had a superior tumour-to-muscle ratio [188]. Several factors could explain the phenomenon; indeed, some tumours might have a lower than-average redox potential with high concentrations of electron donors causing reduction and trapping of Cu-ATSM in both hypoxic and normoxic areas. This observation does not discount the fact that $\left[{ }^{64} \mathrm{Cu}\right] \mathrm{Cu}-$ ATSM may still be clinically relevant as a tracer for hypoxia, perhaps HIF1 status, as suggested by some investigators [189]. The timing of image acquisition is crucial, as the initial phase of tracer uptake can be perfusion and hypoxia-driven, whereas at later time points uptake is probably more indicative of tumour hypoxia.

\section{Validation of MRI and PET hypoxia imaging}

As discussed thus far, both MRI and PET play an important role in hypoxia imaging. However, there are few reports that compare these two imaging modalities. Preclinically, a clear correlation between $\left[{ }^{18}\right.$ F]FAZA PET image intensities and tumour oxygenation was demonstrated by Tran et al. [190]. $\left[{ }^{18}\right.$ F]FAZA accurately showed improved uptake when rats with subcutaneous rhabdomyosarcomas were treated with air, in contrast to carbogen. This correlated well with an invasive OxyLite probe, although the probe demonstrated a relatively high heterogeneity in the oxygen value measured depending on the specific point within the tumour. Functional MRI ( $\left[{ }^{19} \mathrm{~F}\right] \mathrm{MRI}$, however, did not show any discernible difference in T1 spin-lattice relaxation time. In a more recent study, Valable et al. validated tissue saturation studied by MRI against FMISO PET wth high sensitivity and specificity in a rat glioma model [191].

In the clinical setting, Swanson et al. performed a detailed spatial analysis of the hypoxic tumour burden visible on the FMISO PET relative to the imaging changes associated with tumour neovasculature, necrosis, invasion, and edema seen on gadolinium-enhanced T1-weighted MRI (T1Gd) in 24 patients with glioblastoma [152]. Hypoxic Volume (HV), defined within the tumour as sections that had a tumour-to-blood ratio of higher than 1.2, showed a consistent correlation with the MRI-defined regions within the tumour, supporting the idea that there is a definite link between the PET and MRI images of hypoxia. Furthermore, it was found that HV, and the respective surface areas of $\mathrm{HV}$ and T1Gd abnormality were the most significant predictors of survival. Simoncic et al., showed a strong correlation between FMISO PET and dynamic contrast enhanced MRI (DCE-MRI) kinetic parameters in 6 head and neck cancer patients [192].
These studies suggest that both MRI and PET could complement each other and provide a future direction in selecting the best modality to image hypoxia.

\section{Clinical applications}

There is evidence from numerous clinical studies across a range of tumour types to support the existence and importance of the "hypoxia driver" phenotype both in preclinical [193-219] (Table 4) and clinical studies [220-247] (Table 5).

\section{Identification of tumour hypoxia and prediction of prognosis/response to treatment}

The clinical significance of hypoxia PET imaging is to identify individuals with poor prognosis and those likely to benefit from hypoxia-targeted therapy. Several studies have shown that hypoxia PET imaging predicts outcome. High FMISO retention has been associated with higher risk of loco-regional failure and shorter progression-free survival in head-and-neck [142, 248, 249, 252-254] and renal cancer [158]. Furthermore, a meta-review of the clinical data of over 300 patients concluded that FMISO is a predictor of poor treatment response and prognosis [131]. Similarly, FETNIM uptake in lung [176], head-and-neck [175], and oesophageal cancer [180], were also associated with poor outcomes. Studies conducted with FAZA in squamous cell carcinomas of the head and neck [167] and $\mathrm{Cu}$-ATSM in patients with cervical $[125,261,263]$, lung [125, 261], and rectal cancer [262] have shown that lower tumour-to-muscle ratio (TMR) is indicative of better prognosis.

These findings have been discussed in a recent metaanalysis of PET hypoxia studies which have demonstrated a common tendency towards predicting outcome in tumours showing higher tracer accumulation [162]. Decreased FMISO uptake with treatment has been widely reported in brain [152], head-and-neck [250, 255], lung [258, 260], and renal tumours [158]; although this was not seen in some tumours $[142,156]$. Decrease in semi-quantitative imaging parameters such as tumour-to-muscle ratios (TMRs) signifying response to chemotherapy have also been demonstrated with Cu-ATSM in lung [125, 261] and head-and-neck tumours [257], and FAZA in lung cancer [165].

\section{Radiotherapy planning}

It is well known that tumours demonstrate temporal changes and/or heterogeneity in the spatial distribution of hypoxia. Identification of these areas with PET hypoxia scans enables image guidance and hence, radiation dose 
Table 4 Preclinical studies of hypoxia imaging

\section{FMISO}

Rasey et al. [213]

Martin et al. [205]

Martin et al. [204]

Troost et al. [216]

Troost et al. [138]

Oehler et al. [153]

Murakami et al. [157]

Hatano et al. [147]

Schutze et al. [219]

FAZA

Sorger et al. [215]

Piert et al. [212]

Chapman et al. [196]

Chang et al. [195]

EF5

Chitneni et al. [197]

Silvoniemi et al. [215]

Chitneni et al. [198]

Ali et al. [193]

HX4

Dubois et al. [200]

Carlin et al. [187]
Uptake of FMISO by V79 multicellular spheroids after $4 \mathrm{~h}$ of incubation with $\left[{ }^{3} \mathrm{H}\right] \mathrm{FMISO}$, provided a visual and a quantitative measure of hypoxia. Autoradiographs revealed heavily labelled cells in an intermediate zone between the well-oxygenated periphery and the necrotic center

Evaluated the relationship between oxygen concentration and $\left[{ }^{3} \mathrm{H}\right] \mathrm{FMISO}$ binding in monolayer preparations of isolated adult rat myocytes. Under anoxic conditions, $\left[{ }^{3} \mathrm{H}\right] \mathrm{FMISO}$ binding after $3 \mathrm{~h}$ was approximately 25 -fold greater than normoxic controls, which reduced to $40 \%$ at a pO2 of $4 \mathrm{mmHg}$. [ ${ }^{3} \mathrm{H}$ ]FMISO uptake was independent of glucose or thiol concentrations, cellular $\mathrm{pH}$, potential confounding variables in the tumour microenvironment

Confirmed that FMISO uptake was independent of blood flow, both in individual tumours and normal tissues

FMISO can be used to monitor treatment-induced changes in tumour hypoxia, similar to that seen with pimonidazole in various tumour models

Established a correlation between pimonidazole staining and FMISO distribution in head-and-neck xenografts. FMISO accumulation was dependent on the presence of hypoxia and on the tumour microarchitecture

It is feasible to distinguish between different tumor responses to DMXAA treatment. A reduction in FMISO uptake was related to reduced perfusion and, therefore, delivery of FMISO, rather than a reduction in tumour hypoxia

Early changes in the tumour microenvironment following anti-angiogenic therapy confirmed tumour starvation with FMISO hypoxia imaging

Intratumoral FMISO distribution reflected tumor hypoxia and expression of the hypoxia related gene product GLUT-1. However, it did not reflect tumor proliferation or glucose metabolism

Showed that pretreatment FMISO hypoxic volume in FaDu hSCC xenografts is prognostic. SUVmax was not associated with local control

In vitro and invivo study in rat carcinosarcoma tumour models comparing FMISO with FAZA, demonstrated similar tracer accumulation in sites of hypoxia on early PET imaging. However, FAZA had faster elimination kinetics and was cleared via the renal system

Confirmed the faster clearance of FAZA in murine mammary carcinoma, squamous cell carcinoma, and pancreatic acinar cell carcinoma. FAZA had a lower tumour/blood ratio compared with FMISO

Sunitinib treatment resulted in improved tumour oxygenation as shown by significant reduction in FAZA uptake in Caki-1 renal cell xenografts. FAZA uptake increased again upon sunitinib withdrawal, indicating a rebound in tumour hypoxia

Demonstrated the feasibility of FAZA PET as an early pharmacodynamic monitor on the efficacy of anticancer agent BAY 87-2243 that targets the mitochondrial complex I and intratumour oxygen levels

Demonstrated the utility of EF5 PET for monitoring early response to tumour treatment with SN30000 (a novel hypoxia-activated prodrug) plus RT in H640 non-small cell lung cancer xenografts

In their evaluation of the relationship between hypoxia (evaluated with EF5 PET) and tumour growth, have demonstrated that uptake of EF5 in the late phase of exponential tumor growth is associated with the tumour growth rate in mice bearing HNC xenografts

Evaluated EF5 tumour uptake versus EF5 binding and hypoxia as determined from immunohistochemistry at both macroscopic and microregional levels. It was shown that the uptake and hypoxia selectivity of $\left[{ }^{18} \mathrm{~F}\right] \mathrm{EF} 5$ varied among tumour models-PC3, HCT116, and H460

Evaluated the relationship between pre-treatment EF5 PET and the response of preclinical tumor models (HT29, A549 and RKO tumours grown in nude mice) to a range of fractionated radiotherapies. Irradiated tumours exhibited reduced EF5 uptake 1 month after treatment compared to control tumours, suggesting that pretreatment EF5 PET can predict the response of tumours to single fraction radiation treatment

In a rhabdomyosarcoma rat tumour model, HX4 binding was dependent on tumoural oxygenation status. A significant spatial relationship was shown between HX4 distribution and pimonidazole staining

In a SQ20b head and neck xenograft mouse model similar tumour to muscle ratios for FMISO, FAZA, and HX4 were seen. The fluorinated nitroimidazoles all showed radiotracer uptake increasing with pimonidazole and CA9 staining. However, (64)Cu-ATSM showed and inverse relationship. However, these results were obtained at 80-90 min post injection, a time point which is probably too early for evaluation since normal tissue clearance is still ongoing. $\mathrm{Cu}$-ATSM had the highest tumour accumulation and low renal clearance compared to fluorinated nitroimidazoles 
Table 4 continued

Peeters et al. [211]

Peeters et al. [210]

\section{FETNIM}

Gronroos et al. [201]

Cu-ATSM

Fujibayashi et al. [124]

Lewis et al. [203]

Ko et al. [202], Obata et al. [209]

O’Donoghue et al. [185]

Burgman et al. [194]

McQuade et al. [208]

Yuan et al. [218]

Matsumoto et al. [206]

Dence et al. [199]

McCall et al. [207]

Valtorta et al. [217]

Hueting et al. [188]
In a comparative study within a rat rhabdomyosarcoma model, FMISO, FAZA, and HX4 uptake (tumour to blood ratio (TBR)), reproducibility and reversibility were assessed. Blood clearance for FAZA and HX4 was similar 3 h p.i., while for FMISO, as expected, clearance from normal tissues was significantly lower. Differences in tumour uptake resulted in significantly higher TBR for HX4 compared to the other tracers. Reproducibility was similar for both FMISO and HX4. Furthermore, decreasing the hypoxic fraction using carbogen resulted in loss of FMISO uptake, whilst modifying the hypoxic fraction by breathing $7 \%$ oxygen further enhanced FAZA and HX4 uptake

Evaluated the efficacy of the hypoxia-activated cytotoxic prodrug TH-302. The hypoxic fraction assessed with HX4 PET imaging in the rhabdomyosarcoma model was significantly reduced at day 4 upon TH-302 treatment, while vehicle treatment was ineffective

Comparison of FMISO and FETNIM uptake in $\mathrm{C} 3 \mathrm{H}$ mammary carcinoma mice model demonstrated equivalence of both the tracers in terms of tumour oxygenation status and intratumoural uptake

Demonstrated that $\left[{ }^{62} \mathrm{Cu}\right] \mathrm{Cu}-\mathrm{ATSM}$ is reduced and retained in hypoxic tissues, whereas it rapidly washes out of normoxic tissues

One of the first $\left[{ }^{64} \mathrm{Cu}\right] \mathrm{Cu}$-ATSM preclinical study in tumour hypoxia imaging in mice bearing EMT6 breast carcinoma cell line, has shown an heterogeneous uptake of the radiotracer (intense uptake was observed in $15-30 \%$ of the tumour)

In an epidermoid rabbit tumour (with a high glycolytic/high hexokinase rate) accumulation of $\left[{ }^{64} \mathrm{Cu}\right] \mathrm{Cu}-\mathrm{ATSM}$ was seen around the outer rim of the tumour masses which on histology correlated with active, viable, and expected hypoxic cells

A good correlation of the intratumour distribution of Cu-ATSM and FMISO was seen at later imaging time points in a $\mathrm{FaDu}$ squamous carcinoma model but not at early time points in an R3327-AT anaplastic rat prostate tumour model. This is consistent with the hypothesis that the spatial distribution of FMISO and $[64 \mathrm{Cu}] \mathrm{Cu}-$ ATSM at later times reflects tumour hypoxia

A similar study indicated that for early images, the distribution of Cu-ATSM was inconsistent with tumour hypoxia and might be more representative of perfusion. Correlation of Cu-ATSM and FMISO uptake at later time points was confirmed. The authors did not dispute the potential utility of Cu-ATSM imaging as a tool, but they pointed out that the mechanism of uptake in hypoxic tumour was unclear

Demonstrated that tumour uptake of hypoxia-selective Cu-ATSM analogues (Cu-ATSE) decreases with increased oxygenation

$\left[{ }^{64} \mathrm{Cu}\right] \mathrm{Cu}-\mathrm{ATSM}$ was shown to be a valid PET hypoxia marker (correlation of the autoradiographic distributions with hypoxia markers as EF5, pimonidazole, and CA9) for adenocarcinoma and glioma tumour cell line, but not in the fibrosarcoma model, where a hypoxia-independent uptake of $\left[{ }^{64} \mathrm{Cu}\right] \mathrm{Cu}$-ATSM was observed

In a direct comparison involving Cu-ATSM, FMISO and pimonidazole in the SCCVII tumour model, uptake of both FMISO and pimonidazole decreased as oxygenation increased, as would be expected for a hypoxia imaging agent, but uptake of Cu-ATSM increased under identical conditions

The affinity of $\left[{ }^{64} \mathrm{Cu}\right] \mathrm{Cu}-\mathrm{ATSM}$ for viable and hypoxic cells was confirmed with the comparison of the regional distribution between $\left[{ }^{64} \mathrm{Cu}\right] \mathrm{Cu}-\mathrm{ATSM}$ and FMISO, FLT, and FDG. A very strong correlation of Cu-ATSM uptake with classical hypoxia (FMISO) and proliferation (FLT) was seen but there was no correlation with metabolic activity (FDG)

Confirmed a rapid tumour uptake and retention of $\left[{ }^{64} \mathrm{Cu}\right] \mathrm{Cu}$-ATSM (tumour-to-muscle ratio was 4:1 within 20 min after injection) with a strong positive spatial correlation to the highly perfused areas. At later time points (18 $\mathrm{h}$ post injection), the tumour-to-muscle ratio was 12:1 and there was no spatial correlation with the perfused areas

Evaluated the kinetics of $\left[{ }^{64} \mathrm{Cu}\right] \mathrm{Cu}$-ATSM distribution using $\left[{ }^{18} \mathrm{~F}\right] \mathrm{FAZA}$ as the gold standard in different xenograft mouse models (FaDu, EMT-6, and PC-3). Cu-ATSM showed a higher tumor-to-muscle ratio than FAZA with overlapping radioactivity distribution profiles in the FaDu mouse model, but heterogeneous distribution in EMT-6 and PC-3 models. This study confirmed the cell-dependent distribution and retention kinetics of $\mathrm{Cu}$-ATSM and underlined the need for proper validation of animal models and PET acquisition protocols before exploration of any new clinical applications

Demonstrated that the distribution of radiocopper from $\mathrm{Cu}$-ATSM in tumours essentially mirrors $\mathrm{Cu}$-acetate suggesting that copper metabolism might play a role in the mechanism of selectivity of Cu-ATSM 
Table 5 Clinical hypoxia PET imaging studies in various tumours

Brain tumours

FMISO

Valk et al. [148]

Bruelhmeier et al. [149]

Cher et al. [151]

Swanson et al. [152]

FRP-170

Shibahara et al. [181] Imaging with FRP-170 PET aids visualisation of hypoxic lesions in 8 patients with glioma. SUVmax correlated positively with HIF-1a immunostaining

Beppu et al. [123] Intratumoural pO2 measured using microelectrodes during tumour resection and HIFa immunostaining correlated with FRP-170 uptake in 12 patients with high-grade gliomas. The mean $\mathrm{pO} 2$ was significantly lower in the areas of high uptake than in those of low uptake, suggesting that high accumulation of FRP-170 might indicate viable hypoxic tissues

$\mathrm{Cu}-\mathrm{ATSM}$

Hino-Shishikura et al. Tumour hypoxia assessed by $\left[{ }^{62} \mathrm{Cu}\right] \mathrm{Cu}-\mathrm{ATSM}$ PET/CT correlates with diffusion capacity obtained by diffusion $[225]$

Head and neck cancer (HNC)

FMISO

Gagel et al. [139]

A correlation was reported between the tumour-to-muscle ratio (TMR), the uptake of FMISO PET and $\mathrm{pO}_{2}$ polarography in 16 patients with HNC, indicating that FMISO-TMR is a suitable method for measuring tumour hypoxia. No correlation between tumour oxygenation status and FDG uptake was seen

Rajendran et al. [150] FMISO imaging detected hypoxia in all tumour types, but there was poor correlation between glucose metabolism and hypoxia

Hicks et al. [141] Positive FMISO uptake in 13 patients. Qualitative decrease in FMISO and FDG uptake induced by therapy

Thorwarth et al. [244] Different types of hypoxia-perfusion patterns identified in tumours

Thorwarth et al. [142] Preradiotherapy FMISO uptake was a prognostic indicator of treatment response to radiotherapy in 12 patients with HNC. There was no correlation between FDG and FMISO tumour uptake

Rajendran et al. [248] In a study of 73 patients with HNC, pretreatment uptake of FMISO was found to be an independent prognostic factor and a stronger predictor of outcome. (Rajendran CCR 2006)

Rajendran et al. [237] Evaluated the feasibility of FMISO guided radiotherapy boost in a patient with $\mathrm{H}$ and $\mathrm{N}$ cancer. This was feasible while respecting the organs at risk tolerance

Rischin et al. [249] FMISO indicated the hypoxia status of each tumour. Higher risk of locoregional failure in hypoxic tumours, while patients on tirapazamine had lower risk of locoregional failure

Zimny et al. [143] In metastatic HNC, FMISO retention is significantly greater in hypoxic tumours than in normoxic tumours, with a strong correlation between the FMISO uptake and Eppendorf pO2 histography readings of $<5 \mathrm{mmHg}$. No correlation was found with FDG

Eschmann et al. [250] Radiotherapy decreased FMISO tumour uptake

Gagel et al. [140]

Lee et al. [251]

Nehmeh et al. [235]

Moderate correlation between oxygen measurements and FMISO uptake. Poor correlation between FDG and FMISO Variable FMISO tumour distribution

Good correlations of intratumour FMISO distributions was seen in 6/13 patients, (consistent with chronic hypoxia) when imaged 3 days apart in a reproducibility study

Dirix et al. [252] Quantitative evaluations of FMISO uptake are expected to play an important role in dose escalation radiotherapy planning. Disease-free survival correlates negatively with baseline tracer uptake and initial hypoxic volume

Okamoto et al. [235] Evaluated the reproducibility of FMISO uptake in HNC in 11 patients on two separate occasions $48 \mathrm{~h}$ apart. FMISO PET can identify hypoxic areas with high reproducibility, thus enabling accurate target delineation during radiotherapy planning 
Table 5 continued

Head and neck cancer (HNC)

Lee et al. [252]

Jansen et al. [225]

Abolmaali et al. [145]

Kikuchi et al. [254]

Yamane et al. [255]

Zips et al. [247]

Sato et al. [146]

Tachibana et al. [243]

Sato et al. [240]

\section{FAZA}

Souvatzoglou et al.

Grosu et al. [166]

Postema et al. [118]

Mortensen et al. [167]

Servagi-Vernat et al.

EF5

Komar et al. [227]

Maity et al. [233]

HX4

Chen et al. [173]

Zegers et al. [246]

\section{FETNIM}

Lehtio et al. [121]

Lehtio et al. [176]

Lehtio et al. [174]

Gronroos et al. [224]
Heterogeneous distribution of FMISO was seen in the primary and/or nodal disease in majority of the patients

Gadopentetate dimeglumine (Gd-DTPA)-based dynamic contrast-enhanced magnetic resonance imaging (DCE-MRI) was combined with FMISO PET in 13 node-positive HNC patients. FMISO uptake negatively correlated with tumour perfusion as assessed by DCE-MRI

\section{FMISO contrast increases $2-4 \mathrm{~h}$ post injection}

Disease-specific survival was significantly lower in patients with high baseline FMISO uptake

FMISO tumour uptake and hypoxic volume significantly decreased after neo-adjuvant chemotherapy in 13 patients with HNC

Hypoxia PET imaging with FMISO after 1 or 2 weeks of radiotherapy correlated better with outcome than imaging pre-treatment

HIF1 expression was strongly correlated with FMISO uptake, but not with FDG uptake, suggesting that FMISO uptake in the primary site of oral squamous cell carcinoma (SCC) indicates a hypoxic environment with HIF1 expression

Showed that 9 of 10 patients with HNC had positive FMISO uptake before radiation therapy. A significant decrease in FMISO uptake was noted at 2 weeks of fractionated radiation therapy in all of the FMISO-positive tumours, indicating reoxygenation during radiotherapy

In a prospective study in 22 patients with oral SCC, FMISO, and FDG PET, done prior to neoadjuvant chemotherapy, demonstrated inverse relation between therapy response and FMISO uptake, whereas the FDG uptake was not significantly correlated with the chemotherapy response. Histological response was used as gold standard

In 11 patients with HCN, FAZA uptake was seen in 7 of 11 primary tumours and 3 of 11 lymph node metastases. Physiological uptake in the kidney and hepatobiliary tree hampered diagnostic interpretation

In patterns of uptake evaluation, FAZA uptake was seen as a single confluent region in 11/18 patients and as multiple diffuse regions in $4 / 18$ patients

High tumour to blood ratio (TBR) in all 7 gliomas; high TBR, SUVmax observed in 6/9 H\&N tumours; moderate TBR, SUVmax in 3/21 lymphomas; increased TBR, SUVmax in 7/11 lung patients

In a small series of 40 patients with HNC, pretreatment tumour hypoxic fraction measured using FAZA PET and an intensity threshold analysis technique was predictive of survival following radiotherapy. High uptake was associated with lower disease-free survival

Semi-quantitative assessment of hypoxic volume using FAZA PET before and during intensity-modulated radiation therapy (IMRT) for 12 patients with locally advanced HNC aids in the delineation of hypoxic volumes for dose escalation protocols

EF5 PET could potentially be a surrogate marker of radioresistance. In 22 patients with HNC, high uptake of the hypoxia tracer EF5 showed a stronger correlation with a poor clinical outcome than FDG uptake

Ongoing trial at the University of Pennsylvanian evaluating reversal of hypoxia in HNC using nelfinavir which may assist the process of re-oxygenation that can occur with fractionated therapy. Patients will be evaluated using EF5 PET before and after the nelfinavir treatment, just prior to radiotherapy

A comparative study in head and neck cancer patients found similar tumour to muscle ratios for HX4 imaging at $1.5 \mathrm{~h}$ p.i. and FMISO imaging at $2 \mathrm{~h} \mathrm{p.i}$

In HNC, hypoxia PET imaging with HX4 provides complementary information to FDG imaging. On average $24 \%$ of the HX4 hypoxic volume was outside the FDG volume

Uptake of FETNIM in HNC is highly variable and seems to be governed by blood flow at least in the early phase of tissue accumulation. Tumour distribution volume correlated strongly with FETNIM uptake and blood flow (measured by $[15 \mathrm{O}] \mathrm{H}_{2} \mathrm{O}$ ), but not with FDG uptake. Values compare favourably with FMISO uptake

Tumour to plasma (T:P) ratio of FETNIM provided an estimate of tumour hypoxia in 10 patients with HNC Patients with higher fractional hypoxic volumes and T:P ratio correlated with poorer survival

In 15 HNC patients treated with radiation, no correlation between FETNIM imaging results and endogenous expression of hypoxia markers such as HIF1 and GLUT-1 was found 
Table 5 continued

Head and neck cancer (HNC)

\section{Cu-ATSM}

Chao et al. [256] Hypoxia imaging with 64Cu-ATSM guided IMRT dose escalation in a phantom study

Minagawa et al. [257] All 5 patients with 64Cu-ATSM SUVmax $<5$ were complete responders

Breast cancer

FMISO

Cheng et al. Showed that there is correlation between FMISO uptake and endocrine therapy outcome and poor correlation between

[154] FMISO uptake and HIF-1a immunostaining

Lung cancer

FMISO

Koh et al. [258] In a study of 7 patients with non-small-cell lung cancer (NSCLC), no correlation between tumour size and fractional hypoxic volume, defined by FMISO PET, was observed. Radiotherapy reduced median fractional hypoxic volume from 58 to $22 \%$

Eschmann et al. FMISO scans performed preradiotherapy in a group of 14 patients with NSCLC: a high TMR and tumour/mediastinal [259] ratio was associated with a higher risk of relapse. FMISO imaging could identify postradiotherapy tumour recurrence due to differential uptake of tracer

Cherk et al. [155] In 21 patients with NSCLC, low FMISO uptake was seen, with no correlation with FDG uptake and surrogate tissue markers of hypoxia, such as microvessel density and GLUT1 and angiogenesis

Gagel et al. [260] In 8 patients with NSCLC treated with a combination of chemotherapy and/or radiotherapy, a decrease in FDG and FMISO uptake after treatment was associated with a favourable outcome, and a high initial FMISO uptake was a poor prognostic indicator

Vera et al. [156] FMISO uptake higher in tumours than in nodes and did not change during therapy

Thureau et al. [245] Low reproducibility and inter-observer agreement for FMISO volume measurements on the basis of visual assessment

Francis et al. [222] Visual analysis demonstrated tumour FMISO activity in 17 of 20 patients with malignant mesothelioma. This pilot study confirmed that mesothelioma is a tumour with significant areas of hypoxia, particularly in dominant tumour masses

FAZA

Bollineni et al. $\quad$ FAZA PET is able to detect heterogeneous distributions of hypoxic sub-volumes on visual analysis. No significant

Trinkhaus et al.

HX4

Zegers et al. [174] correlation between FAZA uptake and FDG SUVmax or lesion size

11/17 patients had baseline hypoxia, 6/8 patients with scans following chemoradiation had resolution of hypoxia based on qualitative assessment

\section{FETNIM}

Li 1 et al. [177]

In NSCLC patients, image contrast was found to be superior $4 \mathrm{~h}$ p.i. compared with earlier time points and uptake patterns were strongly correlated between two scans

Hu m et al. [178] FETNIM uptake was higher in tumours than in normal tissue. Similar data observed at 60 and $120 \mathrm{~min}$ p.i

FRP-170

Kaneta et al. [182] FRP-170 accumulation in normal lung shows stable tumour to blood ratio at 60-120 min p.i. Images may allow evaluation of tumour accumulation in a clinical setting

Cu-ATSM

Dehdasthi et al. Imaging with $\left[{ }^{60} \mathrm{Cu}\right] \mathrm{Cu}$-ATSM is feasible in NSCLC. In 14 patients with biopsy-proven NSCLC, $\left[{ }^{60} \mathrm{Cu}\right] \mathrm{Cu}-\mathrm{ATSM}$ [261]

uptake predicted response to radiation or chemotherapy

Lohith et al. [232] FDG and $\left[{ }^{62} \mathrm{Cu}\right] \mathrm{Cu}-\mathrm{ATSM}$ had spatially similar distributions in adenocarcinomas

Gastrointestinal tract cancers

FMISO

Roels et al. [239] Mismatch between FDG and FMISO scans. FMISO uptake reduced after therapy

Segard et al.

FMISO accumulation was observed in $2 / 10$ patients with pancreatic cancer on the basis of visual analysis

[241] 
Table 5 continued

Gastrointestinal tract cancers

FAZA

Havelund et al. $\quad\left[{ }^{18} \mathrm{~F}\right] \mathrm{FAZA}-\mathrm{PET}$ is feasible for visualisation of hypoxia in rectal cancer

Nascente et al. In patients with pancreatic cancer FAZA PET imaging of hypoxia revealed a range of hypoxic fractions which correlated with pimonidazole staining. These preliminary results provide evidence of clinical feasibility and utility of FAZA PET in pancreatic cancer

\section{FETNIM}

Yue et al. [180] In this study, 11 of 14 tumours with FETNIM uptake responded poorly and only 1 of 14 tumours without uptake failed. High baseline SUVmax associated with poor clinical response

Cu-ATSM

Dietz et al. [262] Median tumour-to-muscle activity ratio of 2.6 discriminated those with worse prognosis from those with better prognosis in patients with rectal cancer. Overall and progression-free survival worse in hypoxic tumours

Genitourinary/gynaecological cancers

\section{FMISO}

Lawrentschuk et al. [228]

Hugonet et al. [158]

Rasey et al. [137]

FAZA

Schuetz et al. [169] 5/15 patients with cervical cancer had visually identifiable tumours

Garcia-Parra et al. [223]

EF5

Lin et al. [231]

\section{FETNIM}

Vercellino et al. [179]

$\mathrm{Cu}-\mathrm{ATSM}$

Dehdasthi et al.

Grigsby et al. [263]

Lewis et al. [230]

Dehdasthi et al. [221] renal tumour oxygenation of $>10 \mathrm{mmHg}$

Reduction in hypoxic volume post-therapy underwent FMISO PET imaging predict development of metastatic disease correlation between FDG and $\left[{ }^{60} \mathrm{Cu}\right] \mathrm{Cu}$-ATSM uptake tumours chronic hypoxia did not change greatly over this interval
In a recent study correlating FMISO uptake with direct pO2 histographic measurements in 17 patients with renal cell carcinoma, the degree of FMISO uptake correlated with low tissue oxygen tension. Mild FMISO uptake may reflect

The first clinical evidence to suggest hypoxia in prostate cancer came from a small study of four patients who

FAZA uptake was not increased in prostate tumours as seen with CA9 immunohistochemistry staining

In a pilot study of 8 patients with cervical carcinoma undergoing chemo-radiotherapy, TMR of $>1.35$ was shown to

High uptake associated with lower progression-free and overall survival in patients with cervical cancer

Tumour uptake of $\left[{ }^{60} \mathrm{Cu}\right] \mathrm{Cu}-\mathrm{ATSM}$ inversely related to progression-free survival and overall survival. No

In 15 patients with cancer of the uterine cervix who were imaged with $\left[{ }^{60} \mathrm{Cu}\right]-\mathrm{ATSM}$, hypoxia as determined by the PET images was a significant independent predictor of tumour recurrence.

Fouryear overall survival estimates were $75 \%$ for patients with non-hypoxic tumours and $33 \%$ for those with hypoxic

$\mathrm{Cu}$-ATSM uptake in 10 patients with cancer of the uterine cervix correlates with prognosis and patient outcome. The uptake pattern was reproducible with two scans 1-9 days apart, suggesting that the microscopic distribution of

Tumour uptake of $\left[{ }^{60} \mathrm{Cu}\right]$-ATSM was inversely related to progression-free survival and cause-specific survival. 3-year progression-free survival of patients with non-hypoxic tumours was $71 \%$, and $28 \%$ for those with hypoxic tumours

\section{Soft tissue sarcoma}

\section{FMISO}

Rajendran et al.

Bentzen et al.

FAZA

Lewin et al. [229] Evaluated the implications of hypoxia in STS, using FAZA PET. Hypoxia was associated with radioresistance, higher local recurrence showing a poor outcome 
escalation to radioresistant sub-volumes [162, 248, 259]. Boosting the dose to intra-tumoural areas of biological resistance (dose painting) is being pursued as a strategy to overcome radioresistance and improve outcomes [264]. This is made possible due to the advances in imaging and radiation treatment planning. The feasibility of this strategy has been investigated in cancers of the head and neck, lung, and brain with Cu-ATSM [256], FMISO [251], and FAZA [166], mostly on anthrophomorphic phantoms [166, 249, 251], and further studies are required for translation into clinical benefit.

\section{Discussion and concluding remarks}

Hypoxia research has a long history; however, accurate and reproducible measurement of clinically relevant hypoxia with high sensitivity continues to evade the scientific community. Although radionuclide measurements of hypoxia started in the early 1980s we are yet to have a widely accepted method. In addition to studies with oxygen electrodes, imaging utilising exognous probes including FMISO-PET, FAZA-PET, HX4, and immunohistochemistry with pimonidazole have been the mainstay of hypoxia assessment in clinical studies; the EU-funded METOXIA consortium for example utilises HX4 for assessment of hypoxia [265]. In the post-genome era, genetic methods are also making an important entrance-with a 26-gene signature in validation for assessing hypoxia [266]. There have been some successes in the use of hypoxia measurements as part of clinical trials: a number of studies confirmed that hypoxia predicts locoregional failure to radiotherapy [81, 267, 268] and chemoradiotherapy with hypoxia-modulated cytotoxin tirapazamine [249]. Conversely, there have been several challenges, in particular poor sensitivity of the methods requiring long assessment periods (as pertains to nitroimidazole PET methods), invasive nature (as pertains to pimonidazole immunohistochemistry), an inability to relate measured output to oxygen tension (as pertains to MRI methods despite high spatial resolution) and wide heterogeneity within and between the tumours of the same patients and temporally with treatment (all methods).

Notably, despite design of newer nitroimidazoles with substantially different physicochemical properties-high hydrophilicity-concomitant improvements in signal-tonoise ratio and, thus, reduction in imaging times, have not been achieved, indicating that the ideal chemical design has not yet been realised. There is also paucity of studies examining heterogeneity of hypoxia using parametric imaging to detect the influence of hypoxia sub-volumes and whether this additional detail will have prognostic or predictive value. With the advent of PET-MRI scanners, it will be feasible to multiplex imaging modalities to provide addition information such as perfusion to increase accuracy of hypoxia measurements or provide complementary information with higher predictive value. Whatever selected method will require assessment of precision of measurement which is non-trivial with such a spatio-temporally evanescent phenomenon as hypoxia.

Thus, it is accepted that hypoxia could have significant prognostic and predictive value in the clinic; however, the best method for hypoxia assessment has in our opinion not been realised.

Acknowledgements Eric Aboagye would like to acknowledge programmatic funding from Cancer Research UK (C2536/A16584) and the UK Medical Research Council (MR/N020782/1).

Authors contrubutions A.Challapalli: Content planning, Literature search and review, Manuscript writing, editing. L. Carroll: Content planning, Literature search and review, Manuscript writing, editing. E.Aboagye: Conception, Content planning, Literature search and review, Manuscript writing, editing.

\section{Compliance with ethics guidelines}

Conflict of interest The authors, Amarnath Challapalli, Laurence Carroll, and Eric Aboagye declare no conflicts of interest.

Informed consent This article does not contain any studies with human or animal subjects performed by the any of the authors.

Open Access This article is distributed under the terms of the Creative Commons Attribution 4.0 International License (http://creative commons.org/licenses/by/4.0/), which permits unrestricted use, distribution, and reproduction in any medium, provided you give appropriate credit to the original author(s) and the source, provide a link to the Creative Commons license, and indicate if changes were made.

\section{References}

1. Brown JM, Wilson WR (2004) Exploiting tumour hypoxia in cancer treatment. Nat Rev Cancer 4(6):437-447. doi:10.1038/ nrc1367

2. Vaupel P (2004) The role of hypoxia-induced factors in tumor progression. Oncologist 9(Suppl 5):10-17. doi:10.1634/theon cologist.9-90005-10

3. Thomlinson RH, Gray LH (1955) The histological structure of some human lung cancers and the possible implications for radiotherapy. Br J Cancer 9(4):539-549

4. Dewhirst MW, Ong ET, Braun RD, Smith B, Klitzman B, Evans SM, Wilson D (1999) Quantification of longitudinal tissue pO2 gradients in window chamber tumours: impact on tumour hypoxia. Br J Cancer 79(11-12):1717-1722. doi:10.1038/sj.bjc. 6690273

5. Chan N, Koritzinsky M, Zhao H, Bindra R, Glazer PM, Powell S, Belmaaza A, Wouters B, Bristow RG (2008) Chronic hypoxia decreases synthesis of homologous recombination proteins to offset chemoresistance and radioresistance. Cancer Res 68(2):605-614. doi:10.1158/0008-5472.CAN-07-5472

6. Luoto KR, Kumareswaran R, Bristow RG (2013) Tumor hypoxia as a driving force in genetic instability. Genome Integr 4(1):5. doi:10.1186/2041-9414-4-5 
7. Brown JM (1979) Evidence for acutely hypoxic cells in mouse tumours, and a possible mechanism of reoxygenation. $\mathrm{Br} \mathrm{J}$ Radiol 52(620):650-656. doi:10.1259/0007-1285-52-620-650

8. Brurberg KG, Graff BA, Olsen DR, Rofstad EK (2004) Tumorline specific $\mathrm{pO}(2)$ fluctuations in human melanoma xenografts. Int J Radiat Oncol Biol Phys 58(2):403-409 (S0360301603019886 [pii])

9. Chaplin DJ, Olive PL, Durand RE (1987) Intermittent blood flow in a murine tumor: radiobiological effects. Cancer Res 47(2):597-601

10. Bayer C, Vaupel P (2012) Acute versus chronic hypoxia in tumors: controversial data concerning time frames and biological consequences. Strahlenther Onkol 188(7):616-627. doi:10. 1007/s00066-012-0085-4

11. Ellingsen C, Ovrebo KM, Galappathi K, Mathiesen B, Rofstad EK (2012) pO(2) fluctuation pattern and cycling hypoxia in human cervical carcinoma and melanoma xenografts. Int $\mathbf{J}$ Radiat Oncol Biol Phys 83(4):1317-1323. doi:10.1016/j.ijrobp. 2011.09.037

12. Vaupel P, Mayer A (2014) Hypoxia in tumors: pathogenesisrelated classification, characterization of hypoxia subtypes, and associated biological and clinical implications. Adv Exp Med Biol 812:19-24. doi:10.1007/978-1-4939-0620-8_3

13. Hsieh CH, Lee CH, Liang JA, Yu CY, Shyu WC (2010) Cycling hypoxia increases U87 glioma cell radioresistance via ROS induced higher and long-term HIF-1 signal transduction activity. Oncol Rep 24(6):1629-1636

14. Rouschop KM, Ramaekers CH, Schaaf MB, Keulers TG, Savelkouls KG, Lambin P, Koritzinsky M, Wouters BG (2009) Autophagy is required during cycling hypoxia to lower production of reactive oxygen species. Radiother Oncol 92(3):411-416. doi:10.1016/j.radonc.2009.06.029

15. Koritzinsky M, Wouters BG (2013) The roles of reactive oxygen species and autophagy in mediating the tolerance of tumor cells to cycling hypoxia. Semin Radiat Oncol 23(4):252-261. doi:10. 1016/j.semradonc.2013.05.006

16. Kato Y, Yashiro M, Fuyuhiro Y, Kashiwagi S, Matsuoka J, Hirakawa T, Noda S, Aomatsu N, Hasegawa T, Matsuzaki T, Sawada T, Ohira M, Hirakawa K (2011) Effects of acute and chronic hypoxia on the radiosensitivity of gastric and esophageal cancer cells. Anticancer Res 31(10):3369-3375 (31/10/ 3369 [pii])

17. Bellot G, Garcia-Medina R, Gounon P, Chiche J, Roux D, Pouyssegur J, Mazure NM (2009) Hypoxia-induced autophagy is mediated through hypoxia-inducible factor induction of BNIP3 and BNIP3L via their BH3 domains. Mol Cell Biol 29(10):2570-2581. doi:10.1128/MCB.00166-09

18. Rofstad EK, Gaustad JV, Egeland TA, Mathiesen B, Galappathi K (2010) Tumors exposed to acute cyclic hypoxic stress show enhanced angiogenesis, perfusion and metastatic dissemination. Int J Cancer 127(7):1535-1546. doi:10.1002/ijc.25176

19. Pires I, Silva F, Queiroga FL, Rodrigues P, Henriques R, Pinto CA, Lopes C (2010) Epithelioid hemangiosarcomas of the bovine urinary bladder: a histologic, immunohistochemical, and ultrastructural examination of four tumors. J Vet Diagn Invest 22(1):116-119 (22/1/116 [pii])

20. Bristow RG, Berlin A, Dal Pra A (2014) An arranged marriage for precision medicine: hypoxia and genomic assays in localized prostate cancer radiotherapy. Br J Radiol 87(1035):20130753. doi:10.1259/bjr.20130753

21. Meijer TW, Kaanders JH, Span PN, Bussink J (2012) Targeting hypoxia, HIF-1, and tumor glucose metabolism to improve radiotherapy efficacy. Clin Cancer Res 18(20):5585-5594. doi:10.1158/1078-0432.CCR-12-0858

22. Zagzag D, Krishnamachary B, Yee H, Okuyama H, Chiriboga L, Ali MA, Melamed J, Semenza GL (2005) Stromal cell-derived factor-1alpha and CXCR4 expression in hemangioblastoma and clear cell-renal cell carcinoma: von Hippel-Lindau loss-offunction induces expression of a ligand and its receptor. Cancer Res 65(14):6178-6188. doi:10.1158/0008-5472.CAN-04-4406

23. Semenza GL (2013) HIF-1 mediates metabolic responses to intratumoral hypoxia and oncogenic mutations. J Clin Invest 123(9):3664-3671. doi:10.1172/JCI67230

24. Guo K, Searfoss G, Krolikowski D, Pagnoni M, Franks C, Clark K, Yu KT, Jaye M, Ivashchenko Y (2001) Hypoxia induces the expression of the pro-apoptotic gene BNIP3. Cell Death Differ 8(4):367-376. doi:10.1038/sj.cdd.4400810

25. Krishnamachary B, Berg-Dixon S, Kelly B, Agani F, Feldser D, Ferreira G, Iyer N, LaRusch J, Pak B, Taghavi P, Semenza GL (2003) Regulation of colon carcinoma cell invasion by hypoxiainducible factor 1. Cancer Res 63(5):1138-1143

26. Krishnamachary B, Zagzag D, Nagasawa H, Rainey K, Okuyama H, Baek JH, Semenza GL (2006) Hypoxia-inducible factor-1-dependent repression of E-cadherin in von HippelLindau tumor suppressor-null renal cell carcinoma mediated by TCF3, ZFHX1A, and ZFHX1B. Cancer Res 66(5):2725-2731. doi:10.1158/0008-5472.CAN-05-3719

27. Azab AK, Hu J, Quang P, Azab F, Pitsillides C, Awwad R, Thompson B, Maiso P, Sun JD, Hart CP, Roccaro AM, Sacco A, Ngo HT, Lin CP, Kung AL, Carrasco RD, Vanderkerken K, Ghobrial IM (2012) Hypoxia promotes dissemination of multiple myeloma through acquisition of epithelial to mesenchymal transition-like features. Blood 119(24):5782-5794. doi:10.1182/ blood-2011-09-380410

28. Wouters BG, Koritzinsky M (2008) Hypoxia signalling through mTOR and the unfolded protein response in cancer. Nat Rev Cancer 8(11):851-864. doi:10.1038/nrc2501

29. Nagelkerke A, Bussink J, Mujcic H, Wouters BG, Lehmann S, Sweep FC, Span PN (2013) Hypoxia stimulates migration of breast cancer cells via the PERK/ATF4/LAMP3-arm of the unfolded protein response. Breast Cancer Res 15(1):R2. doi:10. 1186/bcr3373

30. Nagelkerke A, Bussink J, van der Kogel AJ, Sweep FC, Span PN (2013) The PERK/ATF4/LAMP3-arm of the unfolded protein response affects radioresistance by interfering with the DNA damage response. Radiother Oncol 108(3):415-421. doi:10.1016/j.radonc.2013.06.037

31. Nagelkerke A, Sieuwerts AM, Bussink J, Sweep FC, Look MP, Foekens JA, Martens JW, Span PN (2014) LAMP3 is involved in tamoxifen resistance in breast cancer cells through the modulation of autophagy. Endocr Relat Cancer 21(1):101-112. doi:10.1530/ERC-13-0183

32. Nagelkerke A, Bussink J, Sweep FC (1846) Span PN (2014) The unfolded protein response as a target for cancer therapy. Biochim Biophys Acta 2:277-284. doi:10.1016/j.bbcan.2014.07. 006

33. Leung AK, Sharp PA (2010) MicroRNA functions in stress responses. Mol Cell 40(2):205-215. doi:10.1016/j.molcel.2010. 09.027

34. Tsai YP, Wu KJ (2014) Epigenetic regulation of hypoxia-responsive gene expression: focusing on chromatin and DNA modifications. Int J Cancer 134(2):249-256. doi:10.1002/ijc. 28190

35. Johnson AB, Barton MC (2007) Hypoxia-induced and stressspecific changes in chromatin structure and function. Mutat Res 618(1-2):149-162. doi:10.1016/j.mrfmmm.2006.10.007

36. Graeber TG, Osmanian C, Jacks T, Housman DE, Koch CJ, Lowe SW, Giaccia AJ (1996) Hypoxia-mediated selection of cells with diminished apoptotic potential in solid tumours. Nature 379(6560):88-91. doi:10.1038/379088a0

37. Gillies RJ, Gatenby RA (2007) Adaptive landscapes and emergent phenotypes: why do cancers have high glycolysis? 
J Bioenerg Biomembr 39(3):251-257. doi:10.1007/s10863-0079085-y

38. McFate T, Mohyeldin A, Lu H, Thakar J, Henriques J, Halim $\mathrm{ND}, \mathrm{Wu} \mathrm{H}$, Schell MJ, Tsang TM, Teahan O, Zhou S, Califano JA, Jeoung NH, Harris RA, Verma A (2008) Pyruvate dehydrogenase complex activity controls metabolic and malignant phenotype in cancer cells. J Biol Chem 283(33):22700-22708. doi:10.1074/jbc.M801765200

39. Bristow RG, Hill RP (2008) Hypoxia and metabolism. Hypoxia, DNA repair and genetic instability. Nat Rev Cancer 8(3):180-192. doi:10.1038/nrc2344

40. Brunelle JK, Bell EL, Quesada NM, Vercauteren K, Tiranti V, Zeviani M, Scarpulla RC, Chandel NS (2005) Oxygen sensing requires mitochondrial ROS but not oxidative phosphorylation. Cell Metab 1(6):409-414. doi:10.1016/j.cmet.2005.05.002

41. Carmeliet $P$ (2005) Angiogenesis in life, disease and medicine. Nature 438(7070):932-936. doi:10.1038/nature04478

42. Carmeliet P, Jain RK (2011) Molecular mechanisms and clinical applications of angiogenesis. Nature 473(7347):298-307. doi:10.1038/nature10144

43. de la Puente P, Muz B, Azab F, Azab AK (2013) Cell trafficking of endothelial progenitor cells in tumor progression. Clin Cancer Res 19(13):3360-3368. doi:10.1158/1078-0432.CCR-13-0462

44. Hockel M, Schlenger K, Aral B, Mitze M, Schaffer U, Vaupel P (1996) Association between tumor hypoxia and malignant progression in advanced cancer of the uterine cervix. Cancer Res 56(19):4509-4515

45. Kim JW, Tchernyshyov I, Semenza GL, Dang CV (2006) HIF1-mediated expression of pyruvate dehydrogenase kinase: a metabolic switch required for cellular adaptation to hypoxia. Cell Metab 3(3):177-185. doi:10.1016/j.cmet.2006.02.002

46. Krock BL, Skuli N, Simon MC (2011) Hypoxia-induced angiogenesis: good and evil. Genes Cancer 2(12):1117-1133. doi:10.1177/1947601911423654

47. Lou Y, McDonald PC, Oloumi A, Chia S, Ostlund C, Ahmadi A, Kyle A, Auf dem Keller U, Leung S, Huntsman D, Clarke B, Sutherland BW, Waterhouse D, Bally M, Roskelley C, Overall CM, Minchinton A, Pacchiano F, Carta F, Scozzafava A, Touisni N, Winum JY, Supuran CT, Dedhar S (2011) Targeting tumor hypoxia: suppression of breast tumor growth and metastasis by novel carbonic anhydrase IX inhibitors. Cancer Res 71(9):3364-3376. doi:10.1158/0008-5472.CAN-10-4261

48. Lum JJ, Bui T, Gruber M, Gordan JD, DeBerardinis RJ, Covello KL, Simon MC, Thompson CB (2007) The transcription factor HIF-1alpha plays a critical role in the growth factor-dependent regulation of both aerobic and anaerobic glycolysis. Genes Dev 21(9):1037-1049. doi:10.1101/gad.1529107

49. Pouyssegur J, Dayan F, Mazure NM (2006) Hypoxia signalling in cancer and approaches to enforce tumour regression. Nature 441(7092):437-443. doi:10.1038/nature04871

50. Terris DJ, Ho EY, Ibrahim HZ, Dorie MJ, Kovacs MS, Le QT, Koong AC, Pinto HA, Brown JM (2002) Estimating DNA repair by sequential evaluation of head and neck tumor radiation sensitivity using the comet assay. Arch Otolaryngol Head Neck Surg 128(6):698-702 (ooa00219 [pii])

51. Thiery JP, Sleeman JP (2006) Complex networks orchestrate epithelial-mesenchymal transitions. Nat Rev Mol Cell Biol 7(2):131-142. doi:10.1038/nrm1835

52. Yin J, Miyazaki K, Shaner RL, Merrill AH Jr, Kannagi R (2010) Altered sphingolipid metabolism induced by tumor hypoxianew vistas in glycolipid tumor markers. FEBS Lett 584(9):1872-1878. doi:10.1016/j.febslet.2009.11.019

53. Hockel M, Vaupel P (2001) Tumor hypoxia: definitions and current clinical, biologic, and molecular aspects. J Natl Cancer Inst 93(4):266-276
54. Rademakers SE, Span PN, Kaanders JH, Sweep FC, van der Kogel AJ, Bussink J (2008) Molecular aspects of tumour hypoxia. Mol Oncol 2(1):41-53. doi:10.1016/j.molonc.2008.03. 006

55. Sounni NE, Noel A (2013) Targeting the tumor microenvironment for cancer therapy. Clin Chem 59(1):85-93. doi:10.1373/ clinchem.2012.185363

56. Casazza A, Di Conza G, Wenes M, Finisguerra V, Deschoemaeker S, Mazzone M (2014) Tumor stroma: a complexity dictated by the hypoxic tumor microenvironment. Oncogene 33(14):1743-1754. doi:10.1038/onc.2013.121

57. Tafani M, Pucci B, Russo A, Schito L, Pellegrini L, Perrone GA, Villanova L, Salvatori L, Ravenna L, Petrangeli E, Russo MA (2013) Modulators of HIF1alpha and NFkB in cancer treatment: is it a rational approach for controlling malignant progression? Front Pharmacol 4:13. doi:10.3389/fphar.2013.00013

58. Muz B, de la Puente P, Azab F, Azab AK (2015) The role of hypoxia in cancer progression, angiogenesis, metastasis, and resistance to therapy. Hypoxia (Auckl) 3:83-92. doi:10.2147/ HP.S93413

59. Zeng W, Liu P, Pan W, Singh SR, Wei Y (2015) Hypoxia and hypoxia inducible factors in tumor metabolism. Cancer Lett 356(2 Pt A):263-267 10.1016/j.canlet.2014.01.032

60. Tan Q, Saggar JK, Yu M, Wang M, Tannock IF (2015) Mechanisms of drug resistance related to the microenvironment of solid tumors and possible strategies to inhibit them. Cancer $\mathbf{J}$ 21(4):254-262. doi:10.1097/PPO.0000000000000131

61. Yu M, Ocana A, Tannock IF (2013) Reversal of ATP-binding cassette drug transporter activity to modulate chemoresistance: why has it failed to provide clinical benefit? Cancer Metastasis Rev 32(1-2):211-227. doi:10.1007/s10555-012-9402-8

62. Zhao Q, Li Y, Tan BB, Fan LQ, Yang PG, Tian Y (2015) HIF1alpha induces multidrug resistance in gastric cancer cells by inducing MiR-27a. PLoS One 10(8):e0132746. doi:10.1371/ journal.pone.0132746

63. Chen J, Ding Z, Peng Y, Pan F, Li J, Zou L, Zhang Y, Liang H (2014) HIF-1alpha inhibition reverses multidrug resistance in colon cancer cells via downregulation of MDR1/P-glycoprotein. PLoS One 9(6):e98882. doi:10.1371/journal.pone.0098882

64. Thews O, Gassner B, Kelleher DK, Gekle M (2008) Activity of drug efflux transporters in tumor cells under hypoxic conditions. Adv Exp Med Biol 614:157-164. doi:10.1007/978-0-38774911-2_19

65. Thews O, Gassner B, Kelleher DK, Schwerdt G, Gekle M (2006) Impact of extracellular acidity on the activity of $p$-glycoprotein and the cytotoxicity of chemotherapeutic drugs. Neoplasia 8(2):143-152. doi:10.1593/neo.05697

66. Dorr RT (1992) Bleomycin pharmacology: mechanism of action and resistance, and clinical pharmacokinetics. Semin Oncol 19(2 Suppl 5):3-8

67. Chen J, Stubbe J (2005) Bleomycins: towards better therapeutics. Nat Rev Cancer 5(2):102-112. doi:10.1038/nrc1547

68. Cosse JP, Michiels C (2008) Tumour hypoxia affects the responsiveness of cancer cells to chemotherapy and promotes cancer progression. Anticancer Agents Med Chem 8(7):790-797

69. Hunter FW, Wouters BG, Wilson WR (2016) Hypoxia-activated prodrugs: paths forward in the era of personalised medicine. $\mathrm{Br} \mathrm{J}$ Cancer 114(10):1071-1077. doi:10.1038/bjc.2016.79

70. Minchinton AI, Tannock IF (2006) Drug penetration in solid tumours. Nat Rev Cancer 6(8):583-592. doi:10.1038/nrc1893

71. Du J, Chen Y, Li Q, Han X, Cheng C, Wang Z, Danielpour D, Dunwoodie SL, Bunting KD, Yang YC (2012) HIF-1alpha deletion partially rescues defects of hematopoietic stem cell quiescence caused by Cited 2 deficiency. Blood 119(12):2789-2798. doi:10.1182/blood-2011-10-387902 
72. Das B, Tsuchida R, Malkin D, Koren G, Baruchel S, Yeger H (2008) Hypoxia enhances tumor stemness by increasing the invasive and tumorigenic side population fraction. Stem Cells 26(7):1818-1830. doi:10.1634/stemcells.2007-0724

73. Ishii A, Kimura T, Sadahiro H, Kawano H, Takubo K, Suzuki M, Ikeda E (2016) Histological characterization of the tumorigenic "peri-necrotic niche" harboring quiescent stem-like tumor cells in glioblastoma. PLoS ONE 11(1):e0147366. doi:10.1371/ journal.pone. 0147366

74. Gordan JD, Bertout JA, Hu CJ, Diehl JA, Simon MC (2007) HIF-2alpha promotes hypoxic cell proliferation by enhancing c-myc transcriptional activity. Cancer Cell 11(4):335-347. doi:10.1016/j.ccr.2007.02.006

75. Gordan JD, Thompson CB, Simon MC (2007) HIF and c-Myc: sibling rivals for control of cancer cell metabolism and proliferation. Cancer Cell 12(2):108-113. doi:10.1016/j.ccr.2007.07. 006

76. Sullivan R, Pare GC, Frederiksen LJ, Semenza GL, Graham CH (2008) Hypoxia-induced resistance to anticancer drugs is associated with decreased senescence and requires hypoxia-inducible factor-1 activity. Mol Cancer Ther 7(7):1961-1973. doi:10.1158/1535-7163.MCT-08-0198

77. Barker HE, Paget JT, Khan AA, Harrington KJ (2015) The tumour microenvironment after radiotherapy: mechanisms of resistance and recurrence. Nat Rev Cancer 15(7):409-425. doi:10.1038/nrc3958

78. Hockel M, Knoop C, Schlenger K, Vorndran B, Baussmann E, Mitze M, Knapstein PG, Vaupel P (1993) Intratumoral pO2 predicts survival in advanced cancer of the uterine cervix. Radiother Oncol 26(1):45-50

79. Hockel M, Schlenger K, Knoop C, Vaupel P (1991) Oxygenation of carcinomas of the uterine cervix: evaluation by computerized $\mathrm{O} 2$ tension measurements. Cancer Res 51(22):6098-6102

80. Vaupel P, Schlenger K, Knoop C, Hockel M (1991) Oxygenation of human tumors: evaluation of tissue oxygen distribution in breast cancers by computerized $\mathrm{O} 2$ tension measurements. Cancer Res 51(12):3316-3322

81. Nordsmark M, Bentzen SM, Rudat V, Brizel D, Lartigau E, Stadler P, Becker A, Adam M, Molls M, Dunst J, Terris DJ, Overgaard J (2005) Prognostic value of tumor oxygenation in 397 head and neck tumors after primary radiation therapy. An international multi-center study. Radiother Oncol 77(1):18-24. doi:10.1016/j.radonc.2005.06.038

82. Rudat V, Vanselow B, Wollensack P, Bettscheider C, OsmanAhmet S, Eble MJ, Dietz A (2000) Repeatability and prognostic impact of the pretreatment $\mathrm{pO}(2)$ histography in patients with advanced head and neck cancer. Radiother Oncol 57(1):31-37 (S0167-8140(00)00200-0 [pii])

83. Rudat V, Stadler P, Becker A, Vanselow B, Dietz A, Wannenmacher M, Molls M, Dunst J, Feldmann HJ (2001) Predictive value of the tumor oxygenation by means of pO2 histography in patients with advanced head and neck cancer. Strahlenther Onkol 177(9):462-468

84. Bussink J, Kaanders JH, Strik AM, van der Kogel AJ (2000) Effects of nicotinamide and carbogen on oxygenation in human tumor xenografts measured with luminescense based fiber-optic probes. Radiother Oncol 57(1):21-30 (S0167-8140(00)00275-9 [pii])

85. Kaanders JH, Wijffels KI, Marres HA, Ljungkvist AS, Pop LA, van den Hoogen FJ, de Wilde PC, Bussink J, Raleigh JA, van der Kogel AJ (2002) Pimonidazole binding and tumor vascularity predict for treatment outcome in head and neck cancer. Cancer Res 62(23):7066-7074

86. Evans SM, Du KL, Chalian AA, Mick R, Zhang PJ, Hahn SM, Quon H, Lustig R, Weinstein GS, Koch CJ (2007) Patterns and levels of hypoxia in head and neck squamous cell carcinomas and their relationship to patient outcome. Int J Radiat Oncol Biol Phys 69(4):1024-1031. doi:10.1016/j.ijrobp.2007.04.067

87. Lord EM, Harwell L, Koch CJ (1993) Detection of hypoxic cells by monoclonal antibody recognizing 2-nitroimidazole adducts. Cancer Res 53(23):5721-5726

88. Minchinton AI, Durand RE, Chaplin DJ (1990) Intermittent blood flow in the KHT sarcoma-flow cytometry studies using Hoechst 33342. Br J Cancer 62(2):195-200

89. Chia SK, Wykoff CC, Watson PH, Han C, Leek RD, Pastorek J, Gatter KC, Ratcliffe P, Harris AL (2001) Prognostic significance of a novel hypoxia-regulated marker, carbonic anhydrase IX, in invasive breast carcinoma. J Clin Oncol 19(16):3660-3668. doi:10.1200/jco.2001.19.16.3660

90. Griffiths EA, Pritchard SA, McGrath SM, Valentine HR, Price PM, Welch IM, West CM (2007) Increasing expression of hypoxia-inducible proteins in the Barrett's metaplasia-dysplasiaadenocarcinoma sequence. $\mathrm{Br} \mathrm{J}$ Cancer 96(9):1377-1383. doi:10.1038/sj.bjc.6603744

91. Griffiths EA, Pritchard SA, Valentine HR, Whitchelo N, Bishop PW, Ebert MP, Price PM, Welch IM, West CM (2007) Hypoxiainducible factor-1alpha expression in the gastric carcinogenesis sequence and its prognostic role in gastric and gastro-oesophageal adenocarcinomas. Br J Cancer 96(1):95-103. doi:10. 1038/sj.bjc.6603524

92. Kon-no H, Ishii G, Nagai K, Yoshida J, Nishimura M, Nara M, Fujii T, Murata Y, Miyamoto H, Ochiai A (2006) Carbonic anhydrase IX expression is associated with tumor progression and a poor prognosis of lung adenocarcinoma. Lung Cancer 54(3):409-418. doi:10.1016/j.lungcan.2006.08.017

93. Koukourakis MI, Bentzen SM, Giatromanolaki A, Wilson GD, Daley FM, Saunders MI, Dische S, Sivridis E, Harris AL (2006) Endogenous markers of two separate hypoxia response pathways (hypoxia inducible factor 2 alpha and carbonic anhydrase 9) are associated with radiotherapy failure in head and neck cancer patients recruited in the CHART randomized trial. J Clin Oncol 24(5):727-735. doi:10.1200/JCO.2005.02.7474

94. Bache M, Kappler M, Said HM, Staab A, Vordermark D (2008) Detection and specific targeting of hypoxic regions within solid tumors: current preclinical and clinical strategies. Curr Med Chem 15(4):322-338

95. Baer S, Casaubon L, Schwartz MR, Marcogliese A, Younes M (2002) Glut3 expression in biopsy specimens of laryngeal carcinoma is associated with poor survival. Laryngoscope 112(2):393-396. doi:10.1097/00005537-200202000-00034

96. Mineta H, Miura K, Takebayashi S, Misawa K, Araki K, Misawa Y, Ueda Y (2002) Prognostic value of glucose transporter 1 expression in patients with hypopharyngeal carcinoma. Anticancer Res 22(6B):3489-3494

97. Mineta H, Miura K, Ogino T, Takebayashi S, Misawa K, Ueda Y (2002) Vascular endothelial growth factor (VEGF) expression correlates with p53 and ki-67 expressions in tongue squamous cell carcinoma. Anticancer Res 22(2B):1039-1044

98. O'Connor JP, Boult JK, Jamin Y, Babur M, Finegan KG, Williams KJ, Little RA, Jackson A, Parker GJ, Reynolds AR, Waterton JC, Robinson SP (2016) Oxygen-enhanced MRI accurately identifies, quantifies, and maps tumor hypoxia in preclinical cancer models. Cancer Res 76(4):787-795. doi:10. 1158/0008-5472.CAN-15-2062

99. Mason RP, Shukla H, Antich PP (1993) In vivo oxygen tension and temperature: simultaneous determination using 19F NMR spectroscopy of perfluorocarbon. Magn Reson Med 29(3):296-302

100. Baldwin NJ, Ng TC (1996) Oxygenation and metabolic status of KHT tumors as measured simultaneously by $19 \mathrm{~F}$ magnetic resonance imaging and $31 \mathrm{P}$ magnetic resonance spectroscopy. 
Magn Reson Imaging 14(5):541-551 (0730725X96000495 [pii])

101. Baldwin NJ, Wang Y, Ng TC (1996) In situ 19F MRS measurement of RIF-1 tumor blood volume: corroboration by radioisotope-labeled [125I]-albumin and correlation to tumor size. Magn Reson Imaging 14(3):275-280 (0730725X(95)02080-D [pii])

102. Baudelet C, Gallez B (2002) How does blood oxygen leveldependent (BOLD) contrast correlate with oxygen partial pressure (pO2) inside tumors? Magn Reson Med 48(6):980-986. doi: $10.1002 / \mathrm{mrm} .10318$

103. Fleming IN, Manavaki R, Blower PJ, West C, Williams KJ, Harris AL, Domarkas J, Lord S, Baldry C, Gilbert FJ (2015) Imaging tumour hypoxia with positron emission tomography. $\mathrm{Br}$ J Cancer 112(2):238-250. doi:10.1038/bjc.2014.610

104. Kim YR, Huang IJ, Lee SR, Tejima E, Mandeville JB, van Meer MP, Dai G, Choi YW, Dijkhuizen RM, Lo EH, Rosen BR (2005) Measurements of BOLD/CBV ratio show altered fMRI hemodynamics during stroke recovery in rats. J Cereb Blood Flow Metab 25(7):820-829. doi:10.1038/sj.jcbfm.9600084

105. Leontiev O, Buxton RB (2007) Reproducibility of BOLD, perfusion, and $\mathrm{CMRO} 2$ measurements with calibrated-BOLD fMRI. Neuroimage 35(1):175-184. doi:10.1016/j.neuroimage. 2006.10.044

106. Padhani AR, Krohn KA, Lewis JS, Alber M (2007) Imaging oxygenation of human tumours. Eur Radiol 17(4):861-872. doi:10.1007/s00330-006-0431-y

107. Rijpkema M, Kaanders JH, Joosten FB, van der Kogel AJ, Heerschap A (2002) Effects of breathing a hyperoxic hypercapnic gas mixture on blood oxygenation and vascularity of head-and-neck tumors as measured by magnetic resonance imaging. Int J Radiat Oncol Biol Phys 53(5):1185-1191 (S0360301602028250 [pii])

108. Jiang L, Weatherall PT, McColl RW, Tripathy D, Mason RP (2013) Blood oxygenation level-dependent (BOLD) contrast magnetic resonance imaging (MRI) for prediction of breast cancer chemotherapy response: a pilot study. J Magn Reson Imaging 37(5):1083-1092. doi:10.1002/jmri.23891

109. Tarnawski R, Fowler J, Skladowski K, Swierniak A, Suwinski R, Maciejewski B, Wygoda A (2002) How fast is repopulation of tumor cells during the treatment gap? Int J Radiat Oncol Biol Phys 54(1):229-236 (S036030160202936X [pii])

110. Tarnawski R, Sokol M, Pieniazek P, Maciejewski B, Walecki J, Miszczyk L, Krupska T (2002) 1H-MRS in vivo predicts the early treatment outcome of postoperative radiotherapy for malignant gliomas. Int $\mathrm{J}$ Radiat Oncol Biol Phys 52(5):1271-1276 (S0360301601027699 [pii])

111. Colliez F, Gallez B, Jordan BF (2017) Assessing tumor oxygenation for predicting outcome in radiation oncology: a review of studies correlating tumor hypoxic status and outcome in the preclinical and clinical settings. Front Oncol 7:10. doi:10.3389/ fonc. 2017.00010

112. Chia K, Fleming IN, Blower PJ (2012) Hypoxia imaging with PET: which tracers and why? Nucl Med Commun 33(3):217-222. doi:10.1097/MNM.0b013e32834eacb7

113. Bussink J, van Herpen CM, Kaanders JH, Oyen WJ (2010) PET$\mathrm{CT}$ for response assessment and treatment adaptation in head and neck cancer. Lancet Oncol 11(7):661-669. doi:10.1016/ S1470-2045(09)70353-5

114. Chapman JD, Franko AJ, Sharplin J (1981) A marker for hypoxic cells in tumours with potential clinical applicability. $\mathrm{Br}$ J Cancer 43(4):546-550

115. Chapman JD (1979) Hypoxic sensitizers-implications for radiation therapy. N Engl J Med 301(26):1429-1432. doi:10.1056/ NEJM197912273012606
116. Gronroos T, Minn H (2007) Imaging of tumour hypoxia using PET and 18F-labelled tracers: biology meets technology. Eur J Nucl Med Mol Imaging 34(10):1563-1565. doi:10.1007/ s00259-007-0487-1

117. Yip C, Blower PJ, Goh V, Landau DB, Cook GJ (2015) Molecular imaging of hypoxia in non-small-cell lung cancer. Eur J Nucl Med Mol Imaging 42(6):956-976. doi:10.1007/ s00259-015-3009-6

118. Postema EJ, McEwan AJ, Riauka TA, Kumar P, Richmond DA, Abrams DN, Wiebe LI (2009) Initial results of hypoxia imaging using 1-alpha-D: -(5-deoxy-5-[18F]-fluoroarabinofuranosyl)-2nitroimidazole (18F-FAZA). Eur J Nucl Med Mol Imaging 36(10):1565-1573. doi:10.1007/s00259-009-1154-5

119. Koch CJ, Scheuermann JS, Divgi C, Judy KD, Kachur AV, Freifelder R, Reddin JS, Karp J, Stubbs JB, Hahn SM, Driesbaugh J, Smith D, Prendergast S, Evans SM (2010) Biodistribution and dosimetry of (18)F-EF5 in cancer patients with preliminary comparison of (18)F-EF5 uptake versus EF5 binding in human glioblastoma. Eur $\mathrm{J}$ Nucl Med Mol Imaging 37(11):2048-2059. doi:10.1007/s00259-010-1517-y

120. van Loon J, Janssen MH, Ollers M, Aerts HJ, Dubois L, Hochstenbag M, Dingemans AM, Lalisang R, Brans B, Windhorst B, van Dongen GA, Kolb H, Zhang J, De Ruysscher D, Lambin P (2010) PET imaging of hypoxia using [18F]HX4: a phase I trial. Eur J Nucl Med Mol Imaging 37(9):1663-1668. doi:10.1007/s00259-010-1437-x

121. Lehtio K, Oikonen V, Gronroos T, Eskola O, Kalliokoski K, Bergman J, Solin O, Grenman R, Nuutila P, Minn H (2001) Imaging of blood flow and hypoxia in head and neck cancer: initial evaluation with $[(15) \mathrm{O}] \mathrm{H}(2) \mathrm{O}$ and $[(18) \mathrm{F}]$ fluoroerythronitroimidazole PET. J Nucl Med 42(11):1643-1652

122. Gronroos T, Eskola O, Lehtio K, Minn H, Marjamaki P, Bergman J, Haaparanta M, Forsback S, Solin O (2001) Pharmacokinetics of [18F]FETNIM: a potential marker for PET. J Nucl Med 42(9): 1397-1404

123. Beppu T, Terasaki K, Sasaki T, Fujiwara S, Matsuura H, Ogasawara K, Sera K, Yamada N, Uesugi N, Sugai T, Kudo K, Sasaki M, Ehara S, Iwata R, Takai Y (2014) Standardized uptake value in high uptake area on positron emission tomography with 18F-FRP170 as a hypoxic cell tracer correlates with intratumoral oxygen pressure in glioblastoma. Mol Imaging Biol 16(1):127-135. doi:10.1007/s11307-013-0670-7

124. Fujibayashi Y, Taniuchi H, Yonekura Y, Ohtani H, Konishi J, Yokoyama A (1997) Copper-62-ATSM: a new hypoxia imaging agent with high membrane permeability and low redox potential. J Nucl Med 38(7):1155-1160

125. Dehdashti F, Grigsby PW, Mintun MA, Lewis JS, Siegel BA, Welch MJ (2003) Assessing tumor hypoxia in cervical cancer by positron emission tomography with $60 \mathrm{Cu}$-ATSM: relationship to therapeutic response-a preliminary report. Int J Radiat Oncol Biol Phys 55(5):1233-1238 (S0360301602044772 [pii])

126. Aboagye EO, Kelson AB, Tracy M, Workman P (1998) Preclinical development and current status of the fluorinated 2-nitroimidazole hypoxia probe $\mathrm{N}$-(2-hydroxy-3,3,3trifluoropropyl)-2-(2-nitro-1-imidazolyl) acetamide (SR 4554, CRC 94/17): a non-invasive diagnostic probe for the measurement of tumor hypoxia by magnetic resonance spectroscopy and imaging, and by positron emission tomography. Anticancer Drug Des 13(6):703-730

127. Lee CP, Payne GS, Oregioni A, Ruddle R, Tan S, Raynaud FI, Eaton D, Campbell MJ, Cross K, Halbert G, Tracy M, McNamara J, Seddon B, Leach MO, Workman P, Judson I (2009) A phase I study of the nitroimidazole hypoxia marker SR4554 using 19F magnetic resonance spectroscopy. Br J Cancer 101(11):1860-1868. doi:10.1038/sj.bjc.6605425 
128. Grierson JR, Link JM, Mathis CA, Rasey JS, Krohn KA (1989) A radiosynthesis of fluorine-18 fluoromisonidazole. J Nucl Med 30(3):343-350

129. Krohn KA, Link JM, Mason RP (2008) Molecular imaging of hypoxia. J Nucl Med 49(Suppl 2):129S-148S. doi:10.2967/ jnumed.107.045914

130. Lee ST, Scott AM (2007) Hypoxia positron emission tomography imaging with 18f-fluoromisonidazole. Semin Nucl Med 37(6):451-461. doi:10.1053/j.semnuclmed.2007.07.001

131. Aboagye EO, Lewis AD, Tracy M, Workman P (1997) Bioreductive metabolism of the novel fluorinated 2-nitroimidazole hypoxia probe $\mathrm{N}$-(2-hydroxy-3,3,3-trifluoropropyl)-2-(2-nitroimidazolyl) acetamide (SR-4554). Biochem Pharmacol 54(11):1217-1224 (S0006-2952(97)00344-4 [pii])

132. Hunter FW, Young RJ, Shalev Z, Vellanki RN, Wang J, Gu Y, Joshi N, Sreebhavan S, Weinreb I, Goldstein DP, Moffat J, Ketela T, Brown KR, Koritzinsky M, Solomon B, Rischin D, Wilson WR, Wouters BG (2015) Identification of P450 oxidoreductase as a major determinant of sensitivity to hypoxiaactivated prodrugs. Cancer Res 75(19):4211-4223. doi:10.1158/ 0008-5472.CAN-15-1107

133. Prekeges JL, Rasey JS, Grunbaum Z, Krohn KH (1991) Reduction of fluoromisonidazole, a new imaging agent for hypoxia. Biochem Pharmacol 42(12):2387-2395

134. Jerabek PA, Patrick TB, Kilbourn MR, Dischino DD, Welch MJ (1986) Synthesis and biodistribution of 18F-labeled fluoronitroimidazoles: potential in vivo markers of hypoxic tissue. Int $\mathbf{J}$ Rad Appl Instrum A 37(7):599-605

135. McClelland RA (1990) Molecualr interactions and biological effects of the products of reduction of nitroimidazoles. NATO advanced research workshop on selective activation of drugs by redox processes. Plenum Press, Plattsburgh

136. Cheng X, Bayer C, Maftei CA, Astner ST, Vaupel P, Ziegler SI, Shi K (2014) Preclinical evaluation of parametric image reconstruction of [18F]FMISO PET: correlation with ex vivo immunohistochemistry. Phys Med Biol 59(2):347-362. doi:10. 1088/0031-9155/59/2/347

137. Rasey JS, Koh WJ, Evans ML, Peterson LM, Lewellen TK, Graham MM, Krohn KA (1996) Quantifying regional hypoxia in human tumors with positron emission tomography of [18F]fluoromisonidazole: a pretherapy study of 37 patients. Int J Radiat Oncol Biol Phys 36(2):417-428 (S0360301696003252 [pii])

138. Troost EG, Laverman P, Philippens ME, Lok J, van der Kogel AJ, Oyen WJ, Boerman OC, Kaanders JH, Bussink J (2008) Correlation of [18F]FMISO autoradiography and pimonidazole [corrected] immunohistochemistry in human head and neck carcinoma xenografts. Eur J Nucl Med Mol Imaging 35(10):1803-1811. doi:10.1007/s00259-008-0772-7

139. Gagel B, Reinartz P, Dimartino E, Zimny M, Pinkawa M, Maneschi P, Stanzel S, Hamacher K, Coenen HH, Westhofen M, Bull U, Eble MJ (2004) pO(2) Polarography versus positron emission tomography $([(18) \mathrm{F}]$ fluoromisonidazole, $[(18) \mathrm{F}]-2-$ fluoro-2'-deoxyglucose). An appraisal of radiotherapeutically relevant hypoxia. Strahlenther Onkol 180(10):616-622. doi:10. 1007/s00066-004-1229-y

140. Gagel B, Piroth M, Pinkawa M, Reinartz P, Zimny M, Kaiser HJ, Stanzel S, Asadpour B, Demirel C, Hamacher K, Coenen HH, Scholbach T, Maneschi P, DiMartino E, Eble MJ (2007) pO polarography, contrast enhanced color duplex sonography (CDS), [18F] fluoromisonidazole and [18F] fluorodeoxyglucose positron emission tomography: validated methods for the evaluation of therapy-relevant tumor oxygenation or only bricks in the puzzle of tumor hypoxia? BMC Cancer 7:113. doi:10.1186/ 1471-2407-7-113

141. Hicks RJ, Rischin D, Fisher R, Binns D, Scott AM, Peters LJ (2005) Utility of FMISO PET in advanced head and neck cancer treated with chemoradiation incorporating a hypoxia-targeting chemotherapy agent. Eur J Nucl Med Mol Imaging 32(12):1384-1391. doi:10.1007/s00259-005-1880-2

142. Thorwarth D, Eschmann SM, Holzner F, Paulsen F, Alber M (2006) Combined uptake of [18F]FDG and [18F]FMISO correlates with radiation therapy outcome in head-and-neck cancer patients. Radiother Oncol 80(2):151-156. doi:10.1016/j.radonc. 2006.07.033

143. Zimny M, Gagel B, DiMartino E, Hamacher K, Coenen HH, Westhofen M, Eble M, Buell U, Reinartz P (2006) FDG-a marker of tumour hypoxia? A comparison with [18F]fluoromisonidazole and pO2-polarography in metastatic head and neck cancer. Eur J Nucl Med Mol Imaging 33(12):1426-1431. doi:10.1007/s00259-006-0175-6

144. Mortensen LS, Buus S, Nordsmark M, Bentzen L, Munk OL, Keiding S, Overgaard J (2010) Identifying hypoxia in human tumors: a correlation study between 18F-FMISO PET and the Eppendorf oxygen-sensitive electrode. Acta Oncol 49(7):934-940. doi:10.3109/0284186X.2010.516274

145. Abolmaali N, Haase R, Koch A, Zips D, Steinbach J, Baumann M, Kotzerke J, Zophel K (2011) Two or four hour [(1)(8)F]FMISO-PET in HNSCC. When is the contrast best? Nuklearmedizin 50(1):22-27. doi:10.3413/nukmed-00328-1007

146. Sato J, Kitagawa Y, Yamazaki Y, Hata H, Okamoto S, Shiga T, Shindoh M, Kuge Y, Tamaki N (2013) 18F-fluoromisonidazole PET uptake is correlated with hypoxia-inducible factor-1alpha expression in oral squamous cell carcinoma. J Nucl Med 54(7):1060-1065. doi:10.2967/jnumed.112.114355

147. Hatano T, Zhao S, Zhao Y, Nishijima K, Kuno N, Hanzawa H, Sakamoto T, Tamaki N, Kuge Y (2013) Biological characteristics of intratumoral [F-18]fluoromisonidazole distribution in a rodent model of glioma. Int $\mathbf{J}$ Oncol 42(3):823-830. doi:10. 3892/ijo.2013.1781

148. Valk PE, Mathis CA, Prados MD, Gilbert JC, Budinger TF (1992) Hypoxia in human gliomas: demonstration by PET with fluorine-18-fluoromisonidazole. J Nucl Med 33(12):2133-2137

149. Bruehlmeier M, Roelcke U, Schubiger PA, Ametamey SM (2004) Assessment of hypoxia and perfusion in human brain tumors using PET with $18 \mathrm{~F}$-fluoromisonidazole and $15 \mathrm{O}-\mathrm{H} 2 \mathrm{O}$. J Nucl Med 45(11):1851-1859 (45/11/1851 [pii])

150. Rajendran JG, Mankoff DA, O'Sullivan F, Peterson LM, Schwartz DL, Conrad EU, Spence AM, Muzi M, Farwell DG, Krohn KA (2004) Hypoxia and glucose metabolism in malignant tumors: evaluation by $[18 \mathrm{~F}]$ fluoromisonidazole and [18F]fluorodeoxyglucose positron emission tomography imaging. Clin Cancer Res 10(7):2245-2252

151. Cher LM, Murone C, Lawrentschuk N, Ramdave S, Papenfuss A, Hannah A, O'Keefe GJ, Sachinidis JI, Berlangieri SU, Fabinyi G, Scott AM (2006) Correlation of hypoxic cell fraction and angiogenesis with glucose metabolic rate in gliomas using 18F-fluoromisonidazole, 18F-FDG PET, and immunohistochemical studies. J Nucl Med 47(3):410-418 (47/3/410 [pii])

152. Swanson KR, Chakraborty G, Wang CH, Rockne R, Harpold HL, Muzi M, Adamsen TC, Krohn KA, Spence AM (2009) Complementary but distinct roles for MRI and 18F-fluoromisonidazole PET in the assessment of human glioblastomas. J Nucl Med 50(1):36-44. doi:10.2967/jnumed.108.055467

153. Oehler C, O'Donoghue JA, Russell J, Zanzonico P, Lorenzen S, Ling CC, Carlin S (2011) 18F-fluromisonidazole PET imaging as a biomarker for the response to 5,6-dimethylxanthenone-4acetic acid in colorectal xenograft tumors. J Nucl Med 52(3):437-444. doi:10.2967/jnumed.110.081372

154. Cheng J, Lei L, Xu J, Sun Y, Zhang Y, Wang X, Pan L, Shao Z, Liu G (2013) 18F-fluoromisonidazole PET/CT: a potential tool for predicting primary endocrine therapy resistance in breast 
cancer. J Nucl Med 54(3):333-340. doi:10.2967/jnumed.112. 111963

155. Cherk MH, Foo SS, Poon AM, Knight SR, Murone C, Papenfuss AT, Sachinidis JI, Saunder TH, O'Keefe GJ, Scott AM (2006) Lack of correlation of hypoxic cell fraction and angiogenesis with glucose metabolic rate in non-small cell lung cancer assessed by 18F-Fluoromisonidazole and 18F-FDG PET. J Nucl Med 47(12):1921-1926 (47/12/1921 [pii])

156. Vera P, Bohn P, Edet-Sanson A, Salles A, Hapdey S, Gardin I, Menard JF, Modzelewski R, Thiberville L, Dubray B (2011) Simultaneous positron emission tomography (PET) assessment of metabolism with (1)(8)F-fluoro-2-deoxy-D-glucose (FDG), proliferation with (1)(8)F-fluoro-thymidine (FLT), and hypoxia with (1)(8)fluoro-misonidazole (F-miso) before and during radiotherapy in patients with non-small-cell lung cancer (NSCLC): a pilot study. Radiother Oncol 98(1):109-116. doi:10. 1016/j.radonc.2010.10.011

157. Murakami M, Zhao S, Zhao Y, Chowdhury NF, Yu W, Nishijima K, Takiguchi M, Tamaki N, Kuge Y (2012) Evaluation of changes in the tumor microenvironment after sorafenib therapy by sequential histology and $18 \mathrm{~F}$-fluoromisonidazole hypoxia imaging in renal cell carcinoma. Int J Oncol 41(5):1593-1600. doi:10.3892/ijo.2012.1624

158. Hugonnet F, Fournier L, Medioni J, Smadja C, Hindie E, Huchet V, Itti E, Cuenod CA, Chatellier G, Oudard S, Faraggi M (2011) Metastatic renal cell carcinoma: relationship between initial metastasis hypoxia, change after 1 month's sunitinib, and therapeutic response: an 18F-fluoromisonidazole PET/CT study. J Nucl Med 52(7):1048-1055. doi:10.2967/jnumed.110.084517

159. Piert M (2009) Hypoxia imaging. Principles and practice of PET and PET/CT. Lippincott Williams and Wilkins, Philadelphia

160. Ballinger JR (2001) Imaging hypoxia in tumors. Semin Nucl Med 31(4):321-329

161. Lopci E, Grassi I, Chiti A, Nanni C, Cicoria G, Toschi L, Fonti C, Lodi F, Mattioli S, Fanti S (2014) PET radiopharmaceuticals for imaging of tumor hypoxia: a review of the evidence. Am $\mathbf{J}$ Nucl Med Mol Imaging 4(4):365-384

162. Horsman MR, Mortensen LS, Petersen JB, Busk M, Overgaard J (2012) Imaging hypoxia to improve radiotherapy outcome. Nat Rev Clin Oncol 9(12):674-687. doi:10.1038/nrclinonc.2012.171

163. Barthel $\mathrm{H}$, Wilson $\mathrm{H}$, Collingridge DR, Brown G, Osman S, Luthra SK, Brady F, Workman P, Price PM, Aboagye EO (2004) In vivo evaluation of $[18 \mathrm{~F}]$ fluoroetanidazole as a new marker for imaging tumour hypoxia with positron emission tomography. Br J Cancer 90(11):2232-2242. doi:10.1038/sj.bjc.6601862

164. Bollineni VR, Kerner GS, Pruim J, Steenbakkers RJ, Wiegman EM, Koole MJ, de Groot EH, Willemsen AT, Luurtsema G, Widder J, Groen HJ, Langendijk JA (2013) PET imaging of tumor hypoxia using 18F-fluoroazomycin arabinoside in stage III-IV non-small cell lung cancer patients. J Nucl Med 54(8):1175-1180. doi:10.2967/jnumed.112.115014

165. Trinkaus ME, Blum R, Rischin D, Callahan J, Bressel M, Segard T, Roselt P, Eu P, Binns D, MacManus MP, Ball D, Hicks RJ (2013) Imaging of hypoxia with 18F-FAZA PET in patients with locally advanced non-small cell lung cancer treated with definitive chemoradiotherapy. J Med Imaging Radiat Oncol 57(4):475-481. doi:10.1111/1754-9485.12086

166. Grosu AL, Souvatzoglou M, Roper B, Dobritz M, Wiedenmann N, Jacob V, Wester HJ, Reischl G, Machulla HJ, Schwaiger M, Molls M, Piert M (2007) Hypoxia imaging with FAZA-PET and theoretical considerations with regard to dose painting for individualization of radiotherapy in patients with head and neck cancer. Int J Radiat Oncol Biol Phys 69(2):541-551. doi:10. 1016/j.ijrobp.2007.05.079

167. Mortensen LS, Johansen J, Kallehauge J, Primdahl H, Busk M, Lassen P, Alsner J, Sorensen BS, Toustrup K, Jakobsen S,
Petersen J, Petersen H, Theil J, Nordsmark M, Overgaard J (2012) FAZA PET/CT hypoxia imaging in patients with squamous cell carcinoma of the head and neck treated with radiotherapy: results from the DAHANCA 24 trial. Radiother Oncol 105(1):14-20. doi:10.1016/j.radonc.2012.09.015

168. Souvatzoglou M, Grosu AL, Roper B, Krause BJ, Beck R, Reischl G, Picchio M, Machulla HJ, Wester HJ, Piert M (2007) Tumour hypoxia imaging with [18F]FAZA PET in head and neck cancer patients: a pilot study. Eur J Nucl Med Mol Imaging 34(10):1566-1575. doi:10.1007/s00259-007-0424-3

169. Schuetz M, Schmid MP, Potter R, Kommata S, Georg D, Lukic D, Dudczak R, Kletter K, Dimopoulos J, Karanikas G, Bachtiary B (2010) Evaluating repetitive 18F-fluoroazomycin-arabinoside (18FAZA) PET in the setting of MRI guided adaptive radiotherapy in cervical cancer. Acta Oncol 49(7):941-947. doi:10. 3109/0284186X.2010.510145

170. Havelund BM, Holdgaard PC, Rafaelsen SR, Mortensen LS, Theil J, Bender D, Ploen J, Spindler KL, Jakobsen A (2013) Tumour hypoxia imaging with 18F-fluoroazomycinarabinofuranoside PET/CT in patients with locally advanced rectal cancer. Nucl Med Commun 34(2):155-161. doi:10.1097/MNM. 0b013e32835bd5bc

171. Dolbier WR Jr, Li AR, Koch CJ, Shiue CY, Kachur AV (2001) [18F]-EF5, a marker for PET detection of hypoxia: synthesis of precursor and a new fluorination procedure. Appl Radiat Isot 54(1):73-80 (S0969804300001020 [pii])

172. Dubois L, Landuyt W, Haustermans K, Dupont P, Bormans G, Vermaelen P, Flamen P, Verbeken E, Mortelmans L (2004) Evaluation of hypoxia in an experimental rat tumour model by [(18)F] fluoromisonidazole PET and immunohistochemistry. Br J Cancer 91(11):1947-1954. doi:10.1038/sj.bjc.6602219

173. Chen L, Zhang Z, Kolb HC, Walsh JC, Zhang J, Guan Y (2012) (1)(8)F-HX4 hypoxia imaging with PET/CT in head and neck cancer: a comparison with (1)(8)F-FMISO. Nucl Med Commun 33(10):1096-1102. doi:10.1097/MNM.0b013e3283571016

174. Zegers CM, van Elmpt W, Wierts R, Reymen B, Sharifi H, Ollers MC, Hoebers F, Troost EG, Wanders R, van Baardwijk A, Brans B, Eriksson J, Windhorst B, Mottaghy FM, De Ruysscher D, Lambin P (2013) Hypoxia imaging with [(1)(8)F]HX4 PET in NSCLC patients: defining optimal imaging parameters. Radiother Oncol 109(1):58-64. doi:10.1016/j. radonc.2013.08.031

175. Lehtio K, Eskola O, Viljanen T, Oikonen V, Gronroos T, Sillanmaki L, Grenman R, Minn H (2004) Imaging perfusion and hypoxia with PET to predict radiotherapy response in head-andneck cancer. Int J Radiat Oncol Biol Phys 59(4):971-982. doi:10.1016/j.ijrobp.2003.12.014

176. Lehtio K, Oikonen V, Nyman S, Gronroos T, Roivainen A, Eskola O, Minn H (2003) Quantifying tumour hypoxia with fluorine-18 fluoroerythronitroimidazole ([18F]FETNIM) and PET using the tumour to plasma ratio. Eur J Nucl Med Mol Imaging 30(1):101-108. doi:10.1007/s00259-002-1016-x

177. Li L, Hu M, Zhu H, Zhao W, Yang G, Yu J (2010) Comparison of $18 \mathrm{~F}$-Fluoroerythronitroimidazole and $18 \mathrm{~F}$-fluorodeoxyglucose positron emission tomography and prognostic value in locally advanced non-small-cell lung cancer. Clin Lung Cancer 11(5):335-340. doi:10.3816/CLC.2010.n.042

178. Hu M, Xing L, Mu D, Yang W, Yang G, Kong L, Yu J (2013) Hypoxia imaging with 18F-fluoroerythronitroimidazole integrated PET/CT and immunohistochemical studies in non-small cell lung cancer. Clin Nucl Med 38(8):591-596. doi:10.1097/ RLU.0b013e318279fd3d

179. Vercellino L, Groheux D, Thoury A, Delord M, Schlageter MH, Delpech Y, Barre E, Baruch-Hennequin V, Tylski P, Homyrda L, Walker F, Barranger E, Hindie E (2012) Hypoxia imaging of uterine cervix carcinoma with (18)F-FETNIM PET/CT. Clin 
Nucl Med 37(11):1065-1068. doi:10.1097/RLU. 0b013e3182638e7e

180. Yue J, Yang Y, Cabrera AR, Sun X, Zhao S, Xie P, Zheng J, Ma L, Fu Z, Yu J (2012) Measuring tumor hypoxia with (1)(8)FFETNIM PET in esophageal squamous cell carcinoma: a pilot clinical study. Dis Esophagus 25(1):54-61. doi:10.1111/j.14422050.2011.01209.x

181. Shibahara I, Kumabe T, Kanamori M, Saito R, Sonoda Y, Watanabe M, Iwata R, Higano S, Takanami K, Takai Y, Tominaga $T$ (2010) Imaging of hypoxic lesions in patients with gliomas by using positron emission tomography with 1-(2-[18F] fluoro-1-[hydroxymethyl]ethoxy)methyl-2-nitroimidazole, a new 18F-labeled 2-nitroimidazole analog. J Neurosurg 113(2):358-368. doi:10.3171/2009.10.JNS09510

182. Kaneta T, Takai Y, Iwata R, Hakamatsuka T, Yasuda $H$, Nakayama K, Ishikawa Y, Watanuki S, Furumoto S, Funaki Y, Nakata E, Jingu K, Tsujitani M, Ito M, Fukuda H, Takahashi S, Yamada S (2007) Initial evaluation of dynamic human imaging using 18F-FRP170 as a new PET tracer for imaging hypoxia. Ann Nucl Med 21(2):101-107

183. Obata A, Yoshimi E, Waki A, Lewis JS, Oyama N, Welch MJ, Saji H, Yonekura Y, Fujibayashi Y (2001) Retention mechanism of hypoxia selective nuclear imaging/radiotherapeutic agent cudiacetyl-bis(N4-methylthiosemicarbazone) (Cu-ATSM) in tumor cells. Ann Nucl Med 15(6):499-504

184. Dearling JL, Packard AB (2010) Some thoughts on the mechanism of cellular trapping of $\mathrm{Cu}(\mathrm{II})$-ATSM. Nucl Med Biol 37(3):237-243. doi:10.1016/j.nucmedbio.2009.11.004

185. O'Donoghue JA, Zanzonico P, Pugachev A, Wen B, SmithJones P, Cai S, Burnazi E, Finn RD, Burgman P, Ruan S, Lewis JS, Welch MJ, Ling CC, Humm JL (2005) Assessment of regional tumor hypoxia using $18 \mathrm{~F}$-fluoromisonidazole and 64Cu(II)-diacetyl-bis(N4-methylthiosemicarbazone) positron emission tomography: comparative study featuring microPET imaging, Po2 probe measurement, autoradiography, and fluorescent microscopy in the R3327-AT and $\mathrm{FaDu}$ rat tumor models. Int J Radiat Oncol Biol Phys 61(5):1493-1502. doi:10. 1016/j.ijrobp.2004.12.057

186. Holland JP, Lewis JS, Dehdashti F (2009) Assessing tumor hypoxia by positron emission tomography with $\mathrm{Cu}-\mathrm{ATSM}$. Q J Nucl Med Mol Imaging 53(2):193-200

187. Carlin S, Zhang H, Reese M, Ramos NN, Chen Q, Ricketts SA (2014) A comparison of the imaging characteristics and microregional distribution of 4 hypoxia PET tracers. J Nucl Med 55(3):515-521. doi:10.2967/jnumed.113.126615

188. Hueting R, Kersemans V, Cornelissen B, Tredwell M, Hussien K, Christlieb M, Gee AD, Passchier J, Smart SC, Dilworth JR, Gouverneur V, Muschel RJ (2014) A comparison of the behavior of (64)Cu-acetate and (64)Cu-ATSM in vitro and in vivo. J Nucl Med 55(1):128-134. doi:10.2967/jnumed.113. 119917

189. Tateishi K, Tateishi U, Sato M, Yamanaka S, Kanno H, Murata $\mathrm{H}$, Inoue T, Kawahara N (2013) Application of 62Cu-diacetylbis (N4-methylthiosemicarbazone) PET imaging to predict highly malignant tumor grades and hypoxia-inducible factor1alpha expression in patients with glioma. AJNR Am J Neuroradiol 34(1):92-99. doi:10.3174/ajnr.A3159

190. Tran LB, Bol A, Labar D, Jordan B, Magat J, Mignion L, Gregoire V, Gallez B (2012) Hypoxia imaging with the nitroimidazole 18F-FAZA PET tracer: a comparison with OxyLite, EPR oximetry and 19F-MRI relaxometry. Radiother Oncol 105(1):29-35. doi:10.1016/j.radonc.2012.04.011

191. Valable S, Corroyer-Dulmont A, Chakhoyan A, Durand L, Toutain J, Divoux D, Barre L, MacKenzie ET, Petit E, Bernaudin M, Touzani O, Barbier EL (2016) Imaging of brain oxygenation with magnetic resonance imaging: A validation with positron emission tomography in the healthy and tumoural brain. J Cereb Blood Flow Metab. 271678X16671965. doi:10. 1177/0271678X16671965

192. Simoncic U, Leibfarth S, Welz S, Schwenzer N, Schmidt H, Reischl G, Pfannenberg C, la Fougere C, Nikolaou K, Zips D, Thorwarth D (2017) Comparison of DCE-MRI kinetic parameters and FMISO-PET uptake parameters in head and neck cancer patients. Med Phys. doi:10.1002/mp.12228

193. Ali R, Apte S, Vilalta M, Subbarayan M, Miao Z, Chin FT, Graves EE (2015) 18F-EF5 PET is predictive of response to fractionated radiotherapy in preclinical tumor models. PLoS One 10(10):e0139425. doi:10.1371/journal.pone.0139425

194. Burgman P, O'Donoghue JA, Lewis JS, Welch MJ, Humm JL, Ling CC (2005) Cell line-dependent differences in uptake and retention of the hypoxia-selective nuclear imaging agent $\mathrm{Cu}-$ ATSM. Nucl Med Biol 32(6):623-630. doi:10.1016/j.nucmed bio. 2005.05 .003

195. Chang E, Liu H, Unterschemmann K, Ellinghaus P, Liu S, Gekeler V, Cheng Z, Berndorff D, Gambhir SS (2015) 18FFAZA PET imaging response tracks the reoxygenation of tumors in mice upon treatment with the mitochondrial complex I inhibitor BAY 87-2243. Clin Cancer Res 21(2):335-346. doi:10. 1158/1078-0432.CCR-14-0217

196. Chapman DW, Jans HS, Ma I, Mercer JR, Wiebe LI, Wuest M, Moore RB (2014) Detecting functional changes with [(18)F]FAZA in a renal cell carcinoma mouse model following sunitinib therapy. EJNMMI Res 4(1):27. doi:10.1186/s13550014-0027-5

197. Chitneni SK, Bida GT, Yuan H, Palmer GM, Hay MP, Melcher T, Wilson WR, Zalutsky MR, Dewhirst MW (2013) 18F-EF5 PET imaging as an early response biomarker for the hypoxiaactivated prodrug SN30000 combined with radiation treatment in a non-small cell lung cancer xenograft model. J Nucl Med 54(8):1339-1346. doi:10.2967/jnumed.112.116293

198. Chitneni SK, Bida GT, Zalutsky MR, Dewhirst MW (2014) Comparison of the hypoxia PET tracer (18)F-EF5 to immunohistochemical marker EF5 in 3 different human tumor xenograft models. J Nucl Med 55(7):1192-1197. doi:10.2967/jnumed.114. 137448

199. Dence CS, Ponde DE, Welch MJ, Lewis JS (2008) Autoradiographic and small-animal PET comparisons between (18)FFMISO, (18)F-FDG, (18)F-FLT and the hypoxic selective (64)Cu-ATSM in a rodent model of cancer. Nucl Med Biol 35(6):713-720. doi:10.1016/j.nucmedbio.2008.06.001

200. Dubois LJ, Lieuwes NG, Janssen MH, Peeters WJ, Windhorst AD, Walsh JC, Kolb HC, Ollers MC, Bussink J, van Dongen GA, van der Kogel A, Lambin P (2011) Preclinical evaluation and validation of $[18 \mathrm{~F}] \mathrm{HX} 4$, a promising hypoxia marker for PET imaging. Proc Natl Acad Sci USA 108(35):14620-14625. doi:10.1073/pnas.1102526108

201. Gronroos T, Bentzen L, Marjamaki P, Murata R, Horsman MR, Keiding S, Eskola O, Haaparanta M, Minn H, Solin O (2004) Comparison of the biodistribution of two hypoxia markers [18F]FETNIM and [18F]FMISO in an experimental mammary carcinoma. Eur J Nucl Med Mol Imaging 31(4):513-520. doi:10.1007/s00259-003-1404-X

202. Ko YH, Pedersen PL, Geschwind JF (2001) Glucose catabolism in the rabbit VX2 tumor model for liver cancer: characterization and targeting hexokinase. Cancer Lett 173(1):83-91 (S030438350100667X [pii])

203. Lewis JS, McCarthy DW, McCarthy TJ, Fujibayashi Y, Welch MJ (1999) Evaluation of 64Cu-ATSM in vitro and in vivo in a hypoxic tumor model. J Nucl Med 40(1):177-183

204. Martin GV, Caldwell JH, Graham MM, Grierson JR, Kroll K, Cowan MJ, Lewellen TK, Rasey JS, Casciari JJ, Krohn KA (1992) Noninvasive detection of hypoxic myocardium using 
fluorine-18-fluoromisonidazole and positron emission tomography. J Nucl Med 33(12):2202-2208

205. Martin GV, Cerqueira MD, Caldwell JH, Rasey JS, Embree L, Krohn KA (1990) Fluoromisonidazole. A metabolic marker of myocyte hypoxia. Circ Res 67(1):240-244

206. Matsumoto K, Szajek L, Krishna MC, Cook JA, Seidel J, Grimes K, Carson J, Sowers AL, English S, Green MV, Bacharach SL, Eckelman WC, Mitchell JB (2007) The influence of tumor oxygenation on hypoxia imaging in murine squamous cell carcinoma using $[64 \mathrm{Cu}] \mathrm{Cu}-\mathrm{ATSM}$ or $[18 \mathrm{~F}]$ Fluoromisonidazole positron emission tomography. Int $\mathrm{J}$ Oncol 30(4):873-881

207. McCall KC, Humm JL, Bartlett R, Reese M, Carlin S (2012) Copper-64-diacetyl-bis(N(4)-methylthiosemicarbazone) pharmacokinetics in $\mathrm{FaDu}$ xenograft tumors and correlation with microscopic markers of hypoxia. Int J Radiat Oncol Biol Phys 84(3):e393-e399. doi:10.1016/j.ijrobp.2012.05.005

208. McQuade P, Martin KE, Castle TC, Went MJ, Blower PJ, Welch MJ, Lewis JS (2005) Investigation into 64Cu-labeled Bis(selenosemicarbazone) and Bis(thiosemicarbazone) complexes as hypoxia imaging agents. Nucl Med Biol 32(2):147-156. doi:10. 1016/j.nucmedbio.2004.10.004

209. Obata A, Yoshimoto M, Kasamatsu S, Naiki H, Takamatsu S, Kashikura K, Furukawa T, Lewis JS, Welch MJ, Saji H, Yonekura Y, Fujibayashi Y (2003) Intra-tumoral distribution of (64)Cu-ATSM: a comparison study with FDG. Nucl Med Biol 30(5):529-534 (S0969805103000477 [pii])

210. Peeters SG, Zegers CM, Biemans R, Lieuwes NG, van Stiphout RG, Yaromina A, Sun JD, Hart CP, Windhorst AD, van Elmpt W, Dubois LJ, Lambin P (2015) TH-302 in combination with radiotherapy enhances the therapeutic outcome and is associated with pretreatment [18F]HX4 hypoxia PET imaging. Clin Cancer Res 21(13):2984-2992. doi:10.1158/1078-0432.CCR-15-0018

211. Peeters SG, Zegers CM, Lieuwes NG, van Elmpt W, Eriksson J, van Dongen GA, Dubois L, Lambin P (2015) A comparative study of the hypoxia PET tracers [(1)(8)F]HX4, [(1)(8)F]FAZA, and [(1)(8)F]FMISO in a preclinical tumor model. Int J Radiat Oncol Biol Phys 91(2):351-359. doi:10.1016/j.ijrobp.2014.09. 045

212. Piert M, Machulla HJ, Picchio M, Reischl G, Ziegler S, Kumar P, Wester HJ, Beck R, McEwan AJ, Wiebe LI, Schwaiger M (2005) Hypoxia-specific tumor imaging with $18 \mathrm{~F}$-fluoroazomycin arabinoside. J Nucl Med 46(1):106-113 (46/1/106 [pii])

213. Rasey JS, Grunbaum Z, Krohn K, Nelson N, Chin L (1985) Comparison of binding of $[3 \mathrm{H}]$ misonidazole and [14C]misonidazole in multicell spheroids. Radiat Res 101(3):473-479

214. Silvoniemi A, Silen J, Forsback S, Loyttyniemi E, Schrey AR, Solin O, Grenman R, Minn H, Gronroos TJ (2014) Evaluation of repeated [(18)F]EF5 PET/CT scans and tumor growth rate in experimental head and neck carcinomas. EJNMMI Res 4:65. doi:10.1186/s13550-014-0065-z

215. Sorger D, Patt M, Kumar P, Wiebe LI, Barthel H, Seese A, Dannenberg C, Tannapfel A, Kluge R, Sabri O (2003) [18F]Fluoroazomycinarabinofuranoside (18FAZA) and [18F]Fluoromisonidazole (18FMISO): a comparative study of their selective uptake in hypoxic cells and PET imaging in experimental rat tumors. Nucl Med Biol 30(3):317-326 (S0969805102004420 [pii])

216. Troost EG, Laverman P, Kaanders JH, Philippens M, Lok J, Oyen WJ, van der Kogel AJ, Boerman OC, Bussink J (2006) Imaging hypoxia after oxygenation-modification: comparing [18F]FMISO autoradiography with pimonidazole immunohistochemistry in human xenograft tumors. Radiother Oncol 80(2):157-164. doi:10.1016/j.radonc.2006.07.023
217. Valtorta S, Belloli S, Sanvito F, Masiello V, Di Grigoli G, Monterisi C, Fazio F, Picchio M, Moresco RM (2013) Comparison of $18 \mathrm{~F}$-fluoroazomycin-arabinofuranoside and $64 \mathrm{Cu}$-diacetyl-bis(N4-methylthiosemicarbazone) in preclinical models of cancer. J Nucl Med 54(7):1106-1112. doi:10.2967/jnumed. 112.111120

218. Yuan H, Schroeder T, Bowsher JE, Hedlund LW, Wong T, Dewhirst MW (2006) Intertumoral differences in hypoxia selectivity of the PET imaging agent 64Cu(II)-diacetyl-bis(N4methylthiosemicarbazone). J Nucl Med 47(6):989-998 (47/6/ 989 [pii])

219. Schutze C, Bergmann R, Bruchner K, Mosch B, Yaromina A, Zips D, Hessel F, Krause M, Thames H, Kotzerke J, Steinbach J, Baumann M, Beuthien-Baumann B (2014) Effect of [(18)F]FMISO stratified dose-escalation on local control in $\mathrm{FaDu}$ hSCC in nude mice. Radiother Oncol 111(1):81-87. doi:10.1016/j.radonc.2014.02.005

220. Bentzen L, Keiding S, Nordsmark M, Falborg L, Hansen SB, Keller J, Nielsen OS, Overgaard J (2003) Tumour oxygenation assessed by $18 \mathrm{~F}$-fluoromisonidazole PET and polarographic needle electrodes in human soft tissue tumours. Radiother Oncol 67(3):339-344 (S0167814003000811 [pii])

221. Dehdashti F, Grigsby PW, Lewis JS, Laforest R, Siegel BA, Welch MJ (2008) Assessing tumor hypoxia in cervical cancer by PET with 60Cu-labeled diacetyl-bis(N4-methylthiosemicarbazone). J Nucl Med 49(2):201-205. doi:10.2967/jnumed.107. 048520

222. Francis RJ, Segard T, Morandeau L, Lee YC, Millward MJ, Segal A, Nowak AK (2015) Characterization of hypoxia in malignant pleural mesothelioma with FMISO PET-CT. Lung Cancer 90(1):55-60. doi:10.1016/j.lungcan.2015.07.015

223. Garcia-Parra R, Wood D, Shah RB, Siddiqui J, Hussain H, Park H, Desmond T, Meyer C, Piert M (2011) Investigation on tumor hypoxia in resectable primary prostate cancer as demonstrated by 18 F-FAZA PET/CT utilizing multimodality fusion techniques. Eur J Nucl Med Mol Imaging 38(10):1816-1823. doi:10. 1007/s00259-011-1876-Z

224. Gronroos TJ, Lehtio K, Soderstrom KO, Kronqvist P, Laine J, Eskola O, Viljanen T, Grenman R, Solin O, Minn H (2014) Hypoxia, blood flow and metabolism in squamous-cell carcinoma of the head and neck: correlations between multiple immunohistochemical parameters and PET. BMC Cancer 14:876. doi:10.1186/1471-2407-14-876

225. Hino-Shishikura A, Tateishi U, Shibata H, Yoneyama T, Nishii T, Torii I, Tateishi K, Ohtake M, Kawahara N, Inoue T (2014) Tumor hypoxia and microscopic diffusion capacity in brain tumors: a comparison of (62)Cu-Diacetyl-Bis (N4-Methylthiosemicarbazone) PET/CT and diffusion-weighted MR imaging. Eur J Nucl Med Mol Imaging 41(7):1419-1427. doi:10.1007/ s00259-014-2714-X

226. Jansen JF, Schoder H, Lee NY, Wang Y, Pfister DG, Fury MG, Stambuk HE, Humm JL, Koutcher JA, Shukla-Dave A (2010) Noninvasive assessment of tumor microenvironment using dynamic contrast-enhanced magnetic resonance imaging and 18F-fluoromisonidazole positron emission tomography imaging in neck nodal metastases. Int $\mathrm{J}$ Radiat Oncol Biol Phys 77(5):1403-1410. doi:10.1016/j.ijrobp.2009.07.009

227. Komar G, Lehtio K, Seppanen M, Eskola O, Levola H, Lindholm P, Sipila H, Seppala J, Grenman R, Solin O, Minn H (2014) Prognostic value of tumour blood flow, [(1)(8)F]EF5 and [(1)(8)F]FDG PET/CT imaging in patients with head and neck cancer treated with radiochemotherapy. Eur J Nucl Med Mol Imaging 41(11):2042-2050. doi:10.1007/s00259-014-2818-3

228. Lawrentschuk N (2015) Imaging in prostate cancer with multiparametric magnetic resonance imaging and gallium positron 
emission tomography-computed tomography: the real deal? BJU Int 115(Suppl 5):1-2. doi:10.1111/bju.13094

229. Lewin J, Khamly KK, Young RJ, Mitchell C, Hicks RJ, Toner GC, Ngan SY, Chander S, Powell GJ, Herschtal A, Te Marvelde L, Desai J, Choong PF, Stacker SA, Achen MG, Ferris N, Fox S, Slavin J, Thomas DM (2014) A phase Ib/II translational study of sunitinib with neoadjuvant radiotherapy in soft-tissue sarcoma. Br J Cancer 111(12):2254-2261. doi:10.1038/bjc.2014.537

230. Lewis JS, Laforest R, Dehdashti F, Grigsby PW, Welch MJ, Siegel BA (2008) An imaging comparison of 64Cu-ATSM and $60 \mathrm{Cu}-\mathrm{ATSM}$ in cancer of the uterine cervix. J Nucl Med 49(7):1177-1182. doi:10.2967/jnumed.108.051326

231. Lin LL, Pryma D, Koch C, Evans S (2013) A pilot study of F18 EF5 PET/CT imaging in patients with carcinoma of the cervix. Pract Radiat Oncol 3(2 Suppl 1):S26-S27. doi:10.1016/j.prro. 2013.01.092

232. Lohith TG, Kudo T, Demura Y, Umeda Y, Kiyono Y, Fujibayashi Y, Okazawa H (2009) Pathophysiologic correlation between $62 \mathrm{Cu}-\mathrm{ATSM}$ and $18 \mathrm{~F}-\mathrm{FDG}$ in lung cancer. J Nucl Med 50(12):1948-1953. doi:10.2967/jnumed.109.069021

233. Maity A, Lin A (2014) Using [18F]EF5 PET to measure hypoxia modulation by Nelfinavir in larynx cancer. National Institute of Health, University of Pennsylvania, Philadelphia

234. Nascente CM, Dhani NC, Vines D (2013) Clinical characterization of hypoxia in pancreatic ductal adenocarcinoma (PDAC) by 18F-FAZA PET and pimonidazole. J Clin Oncol 31 (suppl; abstr 4049)

235. Nehmeh SA, Lee NY, Schroder H, Squire O, Zanzonico PB, Erdi YE, Greco C, Mageras G, Pham HS, Larson SM, Ling CC, Humm JL (2008) Reproducibility of intratumor distribution of (18)F-fluoromisonidazole in head and neck cancer. Int J Radiat Oncol Biol Phys 70(1):235-242. doi:10.1016/j.ijrobp.2007.08. 036

236. Okamoto S, Shiga T, Yasuda K, Ito YM, Magota K, Kasai K, Kuge Y, Shirato H, Tamaki N (2013) High reproducibility of tumor hypoxia evaluated by $18 \mathrm{~F}$-fluoromisonidazole PET for head and neck cancer. J Nucl Med 54(2):201-207. doi:10.2967/ jnumed.112.109330

237. Rajendran JG, Hendrickson KR, Spence AM, Muzi M, Krohn KA, Mankoff DA (2006) Hypoxia imaging-directed radiation treatment planning. Eur J Nucl Med Mol Imaging 33(Suppl 1):44-53. doi:10.1007/s00259-006-0135-1

238. Rajendran JG, Wilson DC, Conrad EU, Peterson LM, Bruckner JD, Rasey JS, Chin LK, Hofstrand PD, Grierson JR, Eary JF, Krohn KA (2003) [(18)F]FMISO and [(18)F]FDG PET imaging in soft tissue sarcomas: correlation of hypoxia, metabolism and VEGF expression. Eur J Nucl Med Mol Imaging 30(5):695-704. doi:10.1007/s00259-002-1096-7

239. Roels S, Slagmolen P, Nuyts J, Lee JA, Loeckx D, Maes F, Stroobants S, Penninckx F, Haustermans K (2008) Biological image-guided radiotherapy in rectal cancer: is there a role for FMISO or FLT, next to FDG? Acta Oncol 47(7):1237-1248. doi:10.1080/02841860802256434

240. Sato J, Kitagawa Y, Yamazaki Y, Hata H, Asaka T, Miyakoshi M, Okamoto S, Shiga T, Shindoh M, Kuge Y, Tamaki N (2014) Advantage of FMISO-PET over FDG-PET for predicting histological response to preoperative chemotherapy in patients with oral squamous cell carcinoma. Eur J Nucl Med Mol Imaging 41(11):2031-2041. doi:10.1007/s00259-014-2810-y

241. Segard T, Robins PD, Yusoff IF, Ee H, Morandeau L, Campbell EM, Francis RJ (2013) Detection of hypoxia with 18F-fluoromisonidazole (18F-FMISO) PET/CT in suspected or proven pancreatic cancer. Clin Nucl Med 38(1):1-6. doi:10.1097/RLU. 0b013e3182708777

242. Servagi-Vernat S, Differding S, Hanin FX, Labar D, Bol A, Lee JA, Gregoire V (2014) A prospective clinical study of (1)(8)F-
FAZA PET-CT hypoxia imaging in head and neck squamous cell carcinoma before and during radiation therapy. Eur J Nucl Med Mol Imaging 41(8):1544-1552. doi:10.1007/s00259-0142730-x

243. Tachibana I, Nishimura Y, Shibata T, Kanamori S, Nakamatsu K, Koike R, Nishikawa T, Ishikawa K, Tamura M, Hosono M (2013) A prospective clinical trial of tumor hypoxia imaging with $18 \mathrm{~F}$-fluoromisonidazole positron emission tomography and computed tomography (F-MISO PET/CT) before and during radiation therapy. J Radiat Res 54(6):1078-1084. doi:10.1093/ $\mathrm{jrr} / \mathrm{rrt} 033$

244. Thorwarth D, Eschmann SM, Scheiderbauer J, Paulsen F, Alber M (2005) Kinetic analysis of dynamic 18F-fluoromisonidazole PET correlates with radiation treatment outcome in head-andneck cancer. BMC Cancer 5:152. doi:10.1186/1471-2407-5-152

245. Thureau S, Chaumet-Riffaud P, Modzelewski R, Fernandez P, Tessonnier L, Vervueren L, Cachin F, Berriolo-Riedinger A, Olivier P, Kolesnikov-Gauthier H, Blagosklonov O, Bridji B, Devillers A, Collombier L, Courbon F, Gremillet E, Houzard C, Caignon JM, Roux J, Aide N, Brenot-Rossi I, Doyeux K, Dubray B, Vera P (2013) Interobserver agreement of qualitative analysis and tumor delineation of $18 \mathrm{~F}$-fluoromisonidazole and 3'-deoxy-3'-18F-fluorothymidine PET images in lung cancer. J Nucl Med 54(9):1543-1550. doi:10.2967/jnumed.112.118083

246. Zegers CM, van Elmpt W, Reymen B, Even AJ, Troost EG, Ollers MC, Hoebers FJ, Houben RM, Eriksson J, Windhorst AD, Mottaghy FM, De Ruysscher D, Lambin P (2014) In vivo quantification of hypoxic and metabolic status of NSCLC tumors using [18F]HX4 and [18F]FDG-PET/CT imaging. Clin Cancer Res 20(24):6389-6397. doi:10.1158/1078-0432.CCR14-1524

247. Zips D, Zophel K, Abolmaali N, Perrin R, Abramyuk A, Haase R, Appold S, Steinbach J, Kotzerke J, Baumann M (2012) Exploratory prospective trial of hypoxia-specific PET imaging during radiochemotherapy in patients with locally advanced head-and-neck cancer. Radiother Oncol 105(1):21-28. doi:10. 1016/j.radonc.2012.08.019

248. Rajendran JG, Schwartz DL, O’Sullivan J, Peterson LM, Ng P, Scharnhorst J, Grierson JR, Krohn KA (2006) Tumor hypoxia imaging with [F-18] fluoromisonidazole positron emission tomography in head and neck cancer. Clin Cancer Res 12(18):5435-5441. doi:10.1158/1078-0432.CCR-05-1773

249. Rischin D, Hicks RJ, Fisher R, Binns D, Corry J, Porceddu S, Peters LJ (2006) Prognostic significance of [18F]-misonidazole positron emission tomography-detected tumor hypoxia in patients with advanced head and neck cancer randomly assigned to chemoradiation with or without tirapazamine: a substudy of Trans-Tasman Radiation Oncology Group Study 98.02. J Clin Oncol 24(13):2098-2104. doi:10.1200/JCO.2005.05.2878

250. Eschmann SM, Paulsen F, Bedeshem C, Machulla HJ, Hehr T, Bamberg M, Bares R (2007) Hypoxia-imaging with (18)FMisonidazole and PET: changes of kinetics during radiotherapy of head-and-neck cancer. Radiother Oncol 83(3):406-410. doi:10.1016/j.radonc.2007.05.014

251. Lee NY, Mechalakos JG, Nehmeh S, Lin Z, Squire OD, Cai S, Chan K, Zanzonico PB, Greco C, Ling CC, Humm JL, Schoder H (2008) Fluorine-18-labeled fluoromisonidazole positron emission and computed tomography-guided intensity-modulated radiotherapy for head and neck cancer: a feasibility study. Int J Radiat Oncol Biol Phys 70(1):2-13. doi:10.1016/j.ijrobp.2007.06.039

252. Dirix P, Vandecaveye V, De Keyzer F, Stroobants S, Hermans R, Nuyts S (2009) Dose painting in radiotherapy for head and neck squamous cell carcinoma: value of repeated functional imaging with (18)F-FDG PET, (18)F-fluoromisonidazole PET, diffusion-weighted MRI, and dynamic contrast-enhanced MRI. J Nucl Med 50(7):1020-1027. doi:10.2967/jnumed.109.062638 
253. Lee N, Nehmeh S, Schoder H, Fury M, Chan K, Ling CC, Humm J (2009) Prospective trial incorporating pre-/mid-treatment $[18 \mathrm{~F}]$-misonidazole positron emission tomography for head-and-neck cancer patients undergoing concurrent chemoradiotherapy. Int $\mathrm{J}$ Radiat Oncol Biol Phys 75(1):101-108. doi:10.1016/j.ijrobp.2008.10.049

254. Kikuchi M, Yamane T, Shinohara S, Fujiwara K, Hori SY, Tona Y, Yamazaki H, Naito Y, Senda M (2011) 18F-fluoromisonidazole positron emission tomography before treatment is a predictor of radiotherapy outcome and survival prognosis in patients with head and neck squamous cell carcinoma. Ann Nucl Med 25(9):625-633. doi:10.1007/s12149-011-0508-9

255. Yamane T, Kikuchi M, Shinohara S, Senda M (2011) Reduction of [(18)F]fluoromisonidazole uptake after neoadjuvant chemotherapy for head and neck squamous cell carcinoma. Mol Imaging Biol 13(2):227-231. doi:10.1007/s11307-010-0365-2

256. Chao KS, Bosch WR, Mutic S, Lewis JS, Dehdashti F, Mintun MA, Dempsey JF, Perez CA, Purdy JA, Welch MJ (2001) A novel approach to overcome hypoxic tumor resistance: $\mathrm{Cu}$ ATSM-guided intensity-modulated radiation therapy. Int $\mathbf{J}$ Radiat Oncol Biol Phys 49(4):1171-1182 (S03603016(00)01433-4 [pii])

257. Minagawa Y, Shizukuishi K, Koike I, Horiuchi C, Watanuki K, Hata M, Omura M, Odagiri K, Tohnai I, Inoue T, Tateishi U (2011) Assessment of tumor hypoxia by 62Cu-ATSM PET/CT as a predictor of response in head and neck cancer: a pilot study. Ann Nucl Med 25(5):339-345. doi:10.1007/s12149-011-0471-5

258. Koh WJ, Bergman KS, Rasey JS, Peterson LM, Evans ML, Graham MM, Grierson JR, Lindsley KL, Lewellen TK, Krohn KA et al (1995) Evaluation of oxygenation status during fractionated radiotherapy in human nonsmall cell lung cancers using [F-18]fluoromisonidazole positron emission tomography. Int $\mathbf{J}$ Radiat Oncol Biol Phys 33(2):391-398. doi:10.1016/03603016(95)00170-4

259. Eschmann SM, Paulsen F, Reimold M, Dittmann H, Welz S, Reischl G, Machulla HJ, Bares R (2005) Prognostic impact of hypoxia imaging with $18 \mathrm{~F}$-misonidazole PET in non-small cell lung cancer and head and neck cancer before radiotherapy. J Nucl Med 46(2):253-260 (46/2/253 [pii])

260. Gagel B, Reinartz P, Demirel C, Kaiser HJ, Zimny M, Piroth M, Pinkawa M, Stanzel S, Asadpour B, Hamacher K, Coenen HH, Buell U, Eble MJ (2006) [18F] fluoromisonidazole and [18F] fluorodeoxyglucose positron emission tomography in response evaluation after chemo-/radiotherapy of non-small-cell lung cancer: a feasibility study. BMC Cancer 6:51. doi:10.1186/ 1471-2407-6-51

261. Dehdashti F, Mintun MA, Lewis JS, Bradley J, Govindan R, Laforest R, Welch MJ, Siegel BA (2003) In vivo assessment of tumor hypoxia in lung cancer with 60Cu-ATSM. Eur J Nucl Med Mol Imaging 30(6):844-850. doi:10.1007/s00259-0031130-4

262. Dietz DW, Dehdashti F, Grigsby PW, Malyapa RS, Myerson RJ, Picus J, Ritter J, Lewis JS, Welch MJ, Siegel BA (2008) Tumor hypoxia detected by positron emission tomography with $60 \mathrm{Cu}$ ATSM as a predictor of response and survival in patients undergoing Neoadjuvant chemoradiotherapy for rectal carcinoma: a pilot study. Dis Colon Rectum 51(11):1641-1648. doi:10.1007/s10350-008-9420-3

263. Grigsby PW, Malyapa RS, Higashikubo R, Schwarz JK, Welch MJ, Huettner PC, Dehdashti F (2007) Comparison of molecular markers of hypoxia and imaging with (60)Cu-ATSM in cancer of the uterine cervix. Mol Imaging Biol 9(5):278-283. doi:10. 1007/s11307-007-0095-2

264. Geets X, Gregoire V, Lee JA (2013) Implementation of hypoxia PET imaging in radiation therapy planning. Q J Nucl Med Mol Imaging 57(3):271-282 (R39Y2013N03A0271 [pii])

265. Pettersen EO, Ebbesen P, Gieling RG, Williams KJ, Dubois L, Lambin P, Ward C, Meehan J, Kunkler IH, Langdon SP, Ree AH, Flatmark K, Lyng H, Calzada MJ, Peso LD, Landazuri MO, Gorlach A, Flamm H, Kieninger J, Urban G, Weltin A, Singleton DC, Haider S, Buffa FM, Harris AL, Scozzafava A, Supuran CT, Moser I, Jobst G, Busk M, Toustrup K, Overgaard J, Alsner J, Pouyssegur J, Chiche J, Mazure N, Marchiq I, Parks S, Ahmed A, Ashcroft M, Pastorekova S, Cao Y, Rouschop KM, Wouters BG, Koritzinsky M, Mujcic H, Cojocari D (2015) Targeting tumour hypoxia to prevent cancer metastasis. From biology, biosensing and technology to drug development: the METOXIA consortium. J Enzyme Inhib Med Chem 30(5):689-721. doi:10.3109/14756366.2014.966704

266. Eustace A, Mani N, Span PN, Irlam JJ, Taylor J, Betts GN, Denley H, Miller CJ, Homer JJ, Rojas AM, Hoskin PJ, Buffa FM, Harris AL, Kaanders JH, West CM (2013) A 26-gene hypoxia signature predicts benefit from hypoxia-modifying therapy in laryngeal cancer but not bladder cancer. Clin Cancer Res 19(17):4879-4888. doi:10.1158/1078-0432.CCR-13-0542

267. Fyles AW, Milosevic M, Wong R, Kavanagh MC, Pintilie M, Sun A, Chapman W, Levin W, Manchul L, Keane TJ, Hill RP (1998) Oxygenation predicts radiation response and survival in patients with cervix cancer. Radiother Oncol 48(2):149-156 (S0167-8140(98)00044-9 [pii])

268. Milosevic M, Warde P, Menard C, Chung P, Toi A, Ishkanian A, McLean M, Pintilie M, Sykes J, Gospodarowicz M, Catton C, Hill RP, Bristow R (2012) Tumor hypoxia predicts biochemical failure following radiotherapy for clinically localized prostate cancer. Clin Cancer Res 18(7):2108-2114. doi:10.1158/10780432.CCR-11-2711 